\title{
EXCOMP: An Exposure Comparison Methodology
}

J. C. Lavender

A. L. Franklin

June 1986

Prepared for the U.S. Department of Energy under Contract DE-AC06-76RLO 1830

Pacific Northwest Laboratory Operated for the U.S. Department of Energy by Battelle Memorial Institute 


\title{
DISCLAIMER
}

This report was prepared as an account of work sponsored by an agency of the United States Government. Neither the United States Government nor any agency thereof, nor any of their employees, makes any warranty, express or implied, or assumes any legal liability or responsibility for the accuracy, completeness, or usefulness of any information, apparatus, product, or process disclosed, or represents that its use would not infringe privately owned rights. Reference herein to any specific commercial product, process, or service by trade name, trademark, manufacturer, or otherwise, does not necessarily constitute or imply its endorsement, recommendation, or favoring by the United States Government or any agency thereof. The views and opinions of authors expressed herein do not necessarily state or reflect those of the United States Government or any agency thereof.

\author{
PACIFIC NORTHWEST LABORATORY \\ operated by \\ BATTELLE \\ for the \\ UNITED STATES DEPARTMENT OF ENERGY \\ under Contract DE-AC06-76RLO 1830
}

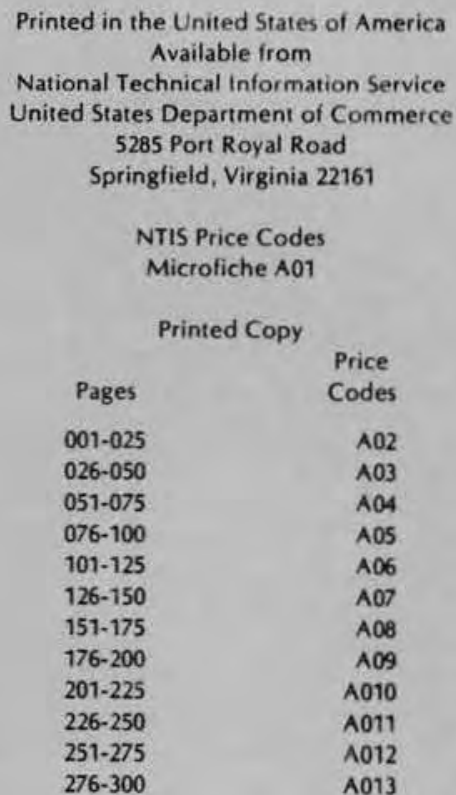


EXCOMP: AN EXPOSURE COMPARISON METHODOLOGY

J. C. Lavender

A. L. Franklin

June 1986

Prepared for

the U.S. Department of Energy

under Contract DE-AC06-76RLO 1830

Pacific Northwest Laboratory

Richland, Washington 99352 


\section{SUMMARY}

EXCOMP is a computerized model that was developed to project occupational exposures based on conceptual designs for the Monitored Retrievable Storage (MRS) Facility. EXCOMP was developed to identify locations and operations in the facility that have a potential for significant occupational exposure rates. Unlike the computerized models that are currently used, EXCOMP is fast and provides the analyst more analysis flexibility.

The analyst has the option of evaluating the occupational exposures for an entire facility, specific work locations, personnel profiles based on employees' job descriptions, or the exposure potential of specific identified sources. Comparative analyses can be performed rapidly by initially analyzing the occupational exposures for a facility or a personnel profile and then modifying the database for selected specific work or source locations.

EXCOMP was developed to provide the analyst a tool that can be used to perform integrated facility evaluations of occupational and public exposures. EXCOMP provides estimates of exposure rates for the purpose of identifying areas with high exposure potential. These areas can be further evaluated using existing detailed exposure modeling computer codes or by performing "hands on" monitoring. 


\section{CONTENTS}

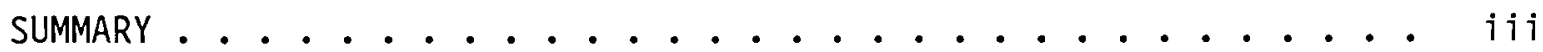

1.0 INTRODUCTION . . . . . . . . . . . . . . . 1.1

1.1 FUTURE APPLICATIONS ......................... 1.3

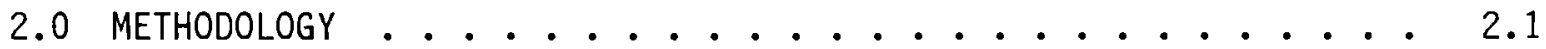

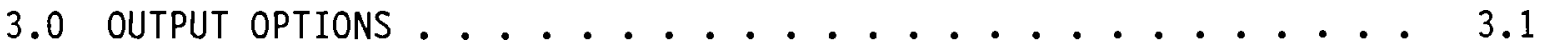

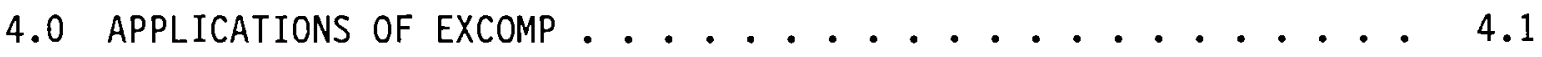

4.1 DESIGN APPLICATION ..................... 4.1

4.2 LICENSING APPLICATION . . . . . . . . . 4.3

4.3 PERSONNEL APPLICATIONS . . . . . . . . . 4.5

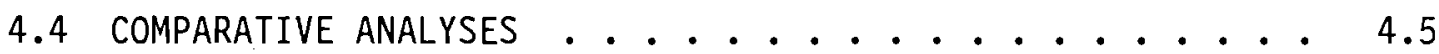

5.0 PROGRAM DESCRIPTION ......................... 5.1

5.1 PROGRAM EXECUTION ...................... 5.1

5.2 DATABASE STRUCTURE $\ldots \ldots \ldots . \ldots . \ldots . \ldots$

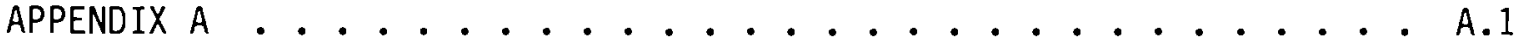

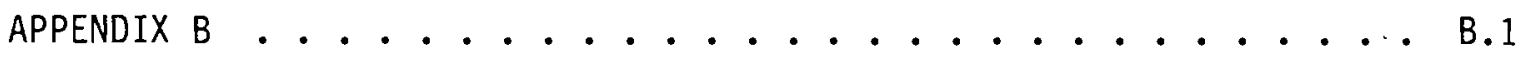

APPENDIX $\mathrm{C} \ldots \ldots \ldots \ldots \ldots \ldots \ldots \ldots \ldots$

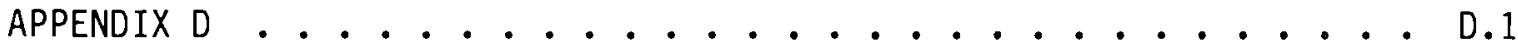

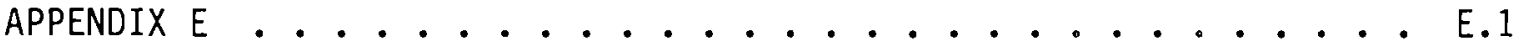




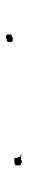




\section{FIGURES}

2.1 structure of EXCOMP .................... 2.2

3.1 Sample Facility Wide Evaluation .............. 3.2

3.2 Sample Specific Work Location . . . . . . . . . 3.3

3.3 Sample Specific Source Location . . . . . . . . . 3.3

3.4 Sample Personnel Profile . . . . . . . . . . . . 3.4

4.1 Design Applications of EXCOMP ............... 4.2

4.2 Licensing Applications of EXCOMP . . . . . . . . . . 4.4

4.3 Personnel Applications of EXCOMP .............. 4.6

5.1 Program Description .................. 5.2

5.2 Example Facility Layout . . . . . . . . . . 5.4

C.1 Simplified Flow Chart of EXCOMP Dose Calculational

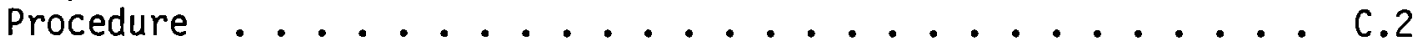




\subsection{INTRODUCTION}

When designing new facilities or modifying existing facilities for handling or processing radioactive material, the radiological exposure of facility personnel and the general public must be carefully considered. The concept developed to control and monitor this exposure is called ALARA (as low as reasonably achievable). The objective of ALARA is to reduce the exposures to personnel and the general public to the lowest levels commensurate with sound economic and operating practices. Therefore, designers and licensing agencies need a method to determine if the ALARA concept has been applied when modifying facilities and when designing new facilities.

Computerized models are the principal method of applying the ALARA concept to a new design. The computerized models that are currently used for exposure evaluations are capable of evaluating only one relationship at a time, i.e., the effects of one source, its strength and location, on one work location. These relationships are user defined and are selected based on the user's judgment. When evaluating a work location that is affected by many sources, the use of current methods can be time consuming and costly. Futhermore, designers or licensees may not have the background to identify locations that should be evaluated or have at their disposal, the information or expertise necessary to perform an appropriate evaluation. Therefore, a need exists for better methods to identify areas and processes within a facility where the potential for significant exposures exist. The results of using this methodology provide a preliminary indication of the impact on occupational exposure from any proposed design work.

A methodology to evaluate exposures (EXCOMP, EXposure COMParison), sponsored by the Monitored Retrievable Storage (MRS) Program Office at Pacific Northwest Laboratory (PNL), was developed to meet these needs. This methodology, which is capable of evaluating each identified work location in a facility with respect to each identified source affecting $i t$, was developed to provide a preliminary and comparative indication of the impacts of various facility designs on occupational exposures. The detail of the facility analyzed is limited by the detail and storage requirements of the database created by the user to characterize the facility. Creation of these databases requires 
a knowledge of the facility layout and operations. The algorithms to calculate the exposure rates, based on distance and shielding are programmed into EXCOMP; therefore, the user will not be required to have a complete understanding of the effects of shielding and/or distance on the exposure received at each work location. EXCOMP simplifies exposure analysis procedures, reduces analysis time and costs, and makes analysis capabilities available to a wider range of potential users. EXCOMP is capable of performing an analysis based on a specific work location or on the complete facility, i.e., a floor by floor analysis, and is primarily intended to be used to perform comparative analyses. A comparative analysis requires an initial evaluation of the facility as currently designed or constructed and operated, followed by an analysis using a modified database to reflect each potential modification to the facility or to the radioactive material. The results from these analyses can be compared to determine if facility or material modifications will significantly reduce the exposures to personnel and the general public.

EXCOMP can perform analyses of exposures to personnel based on a user defined job description or personnel profile, as well as on individual target areas. The personnel profile analysis will project the total daily and quarterly exposure for a particular employee. The analyses performed in these operations are based on the same information used to evaluate the facility from the work or source location perspectives. By projecting employee exposures, EXCOMP provides a tool for management to analyze any opportunities to reduce exposure. Futhermore, decisions to restrict employee movements throughout the facility, or to increase staffing in operations with significant exposure potentials can be made on a more informed basis.

EXCOMP can be used effectively by the operator or the designer of any facility for the handling and storage of radioactive materials. EXCOMP does not require the user to have programming skills, but presently the user will need some knowledge of dBaseIII. In later versions of EXCOMP this requirement will be eliminated. The designer can use the results of the comparative analysis to specify facility modifications, i.e., increasing or decreasing shielding thickness, hence reducing or increasing construction costs. Licensees can use EXCOMP to identify areas where ALARA considerations should be well 
documented. Facility management can use the personnel profile projections to aid in projecting staff requirements.

\subsection{FUTURE APPLICATIONS}

EXCOMP was designed to project occupational exposures at the Monitored Retrievable Storage (MRS) Facility. However, with some minor modifications to the program and new source descriptions, EXCOMP can be used to analyze other facilities and other radioactive or non-radioactive hazardous materials. The information necessary to modify the databases will be determined by the properties of the source and the hazards it represents. In the case of the MRS the hazard is radiological exposure or mrem/hr. For other hazardous materials the controlling factor(s) may be airborne limits or ppm or other limiting conditions of operation.

The essential structure of the methodology used to characterize the facility will remain unchanged. When evaluating different facilities, the new barriers may be filters, walls or containers constructed of different materials. Therefore, the user will be required to identify the new barriers based on their properties with respect to the new sources.

The majority of the changes required will be in the source characterization database. This database identifies the source location, characterizes the source strength, i.e. energy levels, parts per million and the quantity of material at the source location. Therefore, before creating the source database, for any analysis, the user will be required to identify the properties of the source. For airborne hazards this involves determining the various particle sizes and for liquid hazards this involves determining the composition of the solution. 


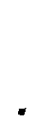




\subsection{METHODOLOGY}

The primary objective in creating EXCOMP was to provide the user a reasonable approximation of the exposure to be received by facility personnel and the general public due to the handling and storage of radioactive materials. By developing information for personnel profiles, work locations and the time spent at those locations, long and short term exposure rates can be projected for a typical employee. These anticipated or projected exposure rates can then be used to perform comparative analyses of the facility design.

ExCOMP has three components (see Figure 2.1). These consist of an interpreter, facility description and source description. The facility description database is used to identify the target locations and the source locations. The source locations identify locations where radioactive materials can be found. This includes hot cells, decon stations, waste processing areas, and lag or field storage locations. The target locations are the locations that are normally occupied by facility personnel. These locations may not necessarily contain sources of radioactive materials. Also identified in this database is the distance in feet and the sum of the thicknesses of the barriers or walls separating the source from the target location.

The source description database is used to identify the source locations, the source type, and to characterize the source with respect to the barriers. The source location is the same source location used in the facility description database. The source type is used for two purposes, the first is to verify that the proper type of source is used for each location, and the second is to establish the quantity of material found at that location. The source strength is characterized and identified as an adjusted MeV. This value is based on the energy levels of each source type and is adjusted by the attenuation value of the barriers present in the facility.

The interpreter prompts the user for the type of analys is to be performed. As an example, if the user is evaluating the total facility or specific work locations the interpreter module reads the facility database and identifies the first or specified target location. For each target location a number of source locations may be considered. When the first source location is identified for that target location, the interpreter module searches the source 


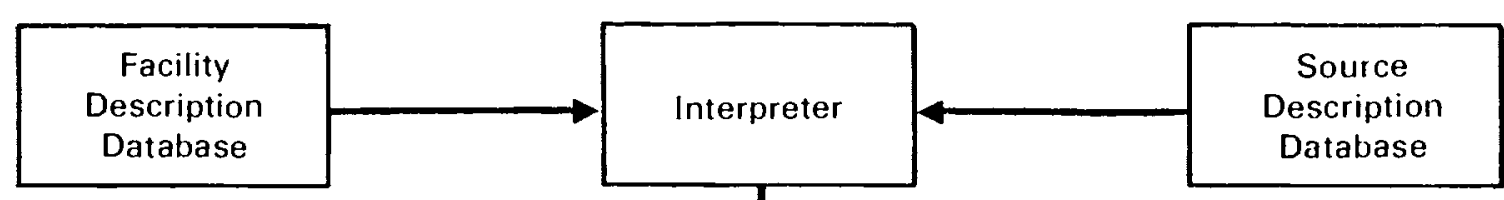

Fields Defined

Target Location

Source Location

Distance in Feet

Barriers (A, B, C)
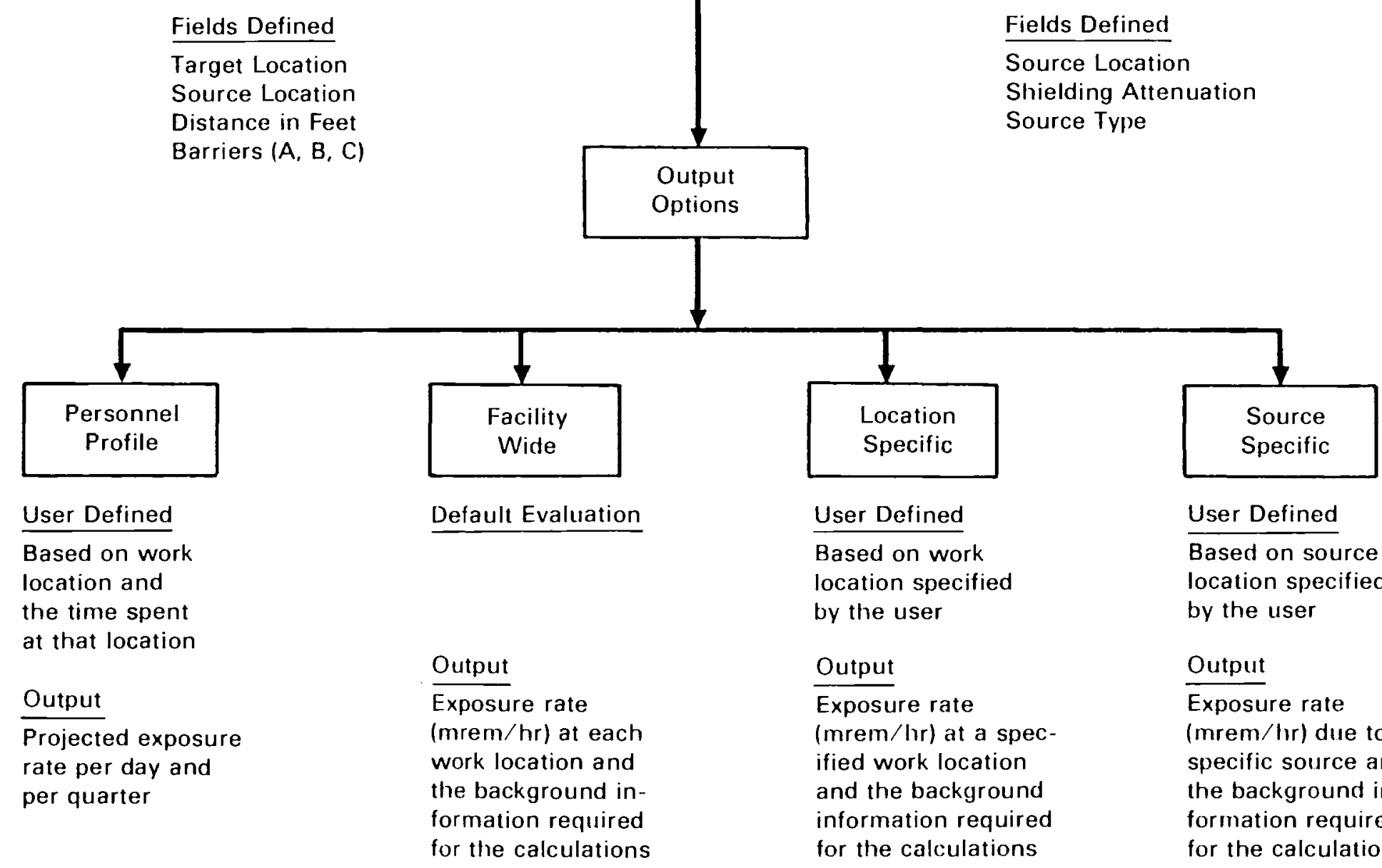

Fields Defined

Source Location

Shielding Attenuation

Source Type

Output

Options

\section{User Defined}

Based on work

location specified

by the user

\section{Output}

Exposure rate

(mrem/hr) at a spec-

ified work location

and the background

information required

for the calculations
User Defined

Based on source

location specified

by the user

\section{Output}

Exposure rate

(mrem/hr) due to a

specific source and

the background in

formation required

for the calculations

FIGURE 2.1. Structure of EXCOMP 
database for that source location. Then using the information in the facility database, i.e. distance to the source, and the thickness of shielding encountered, a radiological exposure is calculated based on the adjusted MeV with respect to the shielding encountered and the distance the target location is from the source. This process is repeated until each target-to-source relationship has been evaluated. 


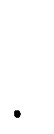

$\cdot$ 


\subsection{OUTPUT OPTIONS}

There are four output options: total facility, specific work locations, specific source locations, and personnel profile. The total facility option is selected when performing the initial evaluation of the facility. The results of this evaluation are the basis of the comparative analysis and are also used to identify locations requiring further investigation or those locations with unacceptable exposure rates. The output from this evaluation (see Figure 3.1) identifies the target location (e.g. the room number), the source location, the distance to the target, the total shielding thickness, the personnel exposure rate, and the type or form of the radioactive material.

The specific work location option is used to examine the exposure potential of one work location. If this option is selected and no modifications have been made to the databases, the results will be identical to the results of the facility wide evaluation (see Figure 3.2 ). Therefore, this option should be selected when investigating a specific location to establish a base case for the comparative analysis or after modifying the facility database with respect to one or more work locations.

The specific source location is used when the investigator wants to adjust the quantity of material at a particular source location. This option does not alter the source database and is useful after performing a comparative analysis indicating that an increase in shielding or distance will not produce satisfactory exposure reductions. The user has the option to reduce or change the type or quantity of material found at that source location. The user also, has the option to increase the weight or type of material found at that source location (see Figure 3.3).

The personnel profile option is used when the user wants to investigate the exposure received by a specific employee type, i.e., manipulator operator, office staff, etc. This analysis provides projected exposure rates for the daily and quarterly exposures received at each of the employee's work locations (see Figure 3.4). These projected results are totaled to indicate the exposure rate an employee of a particular personnel profile will receive due to his/her movements throughout the facility. 
Total Facllity Analysis: Sample Facility

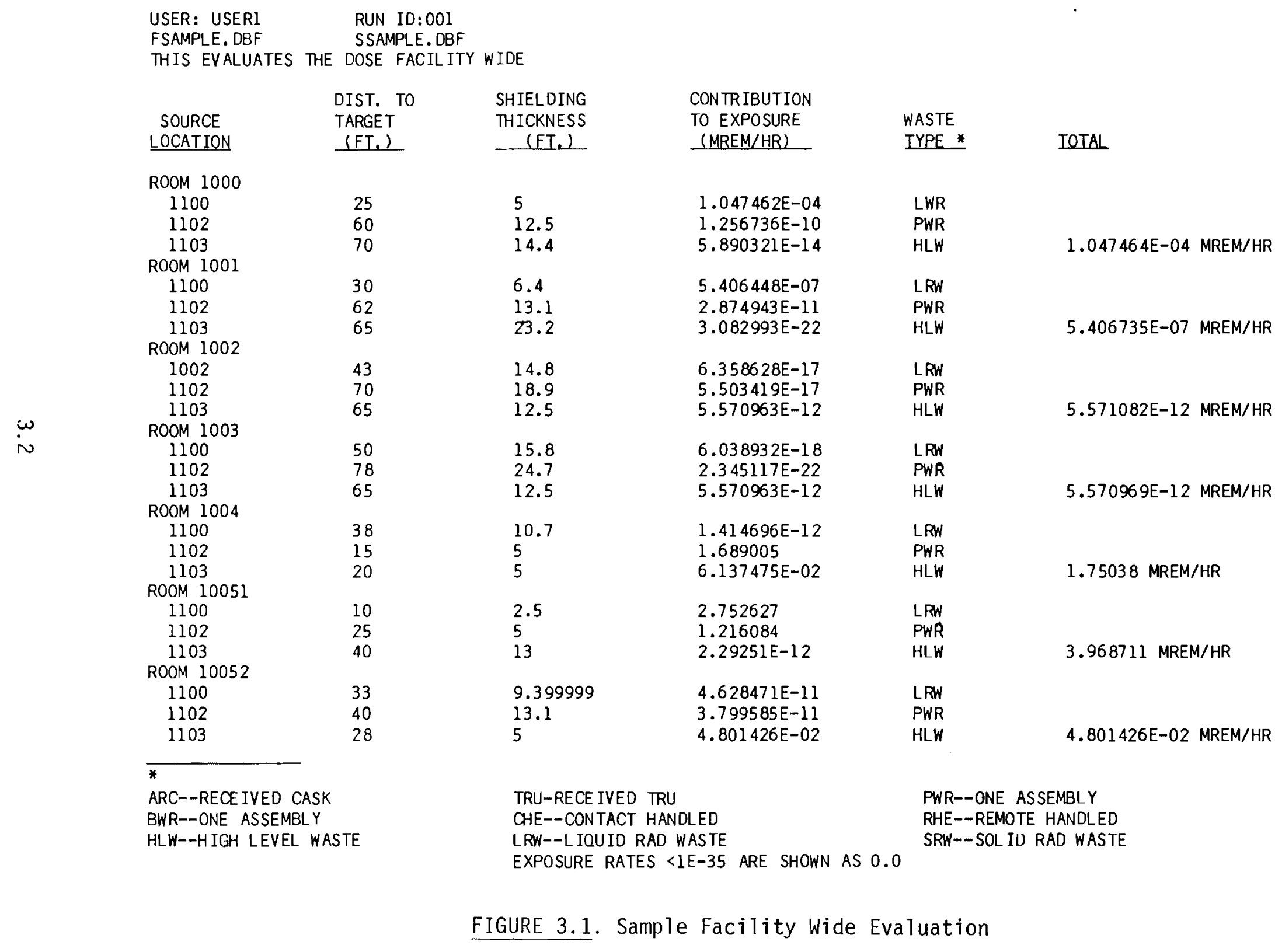




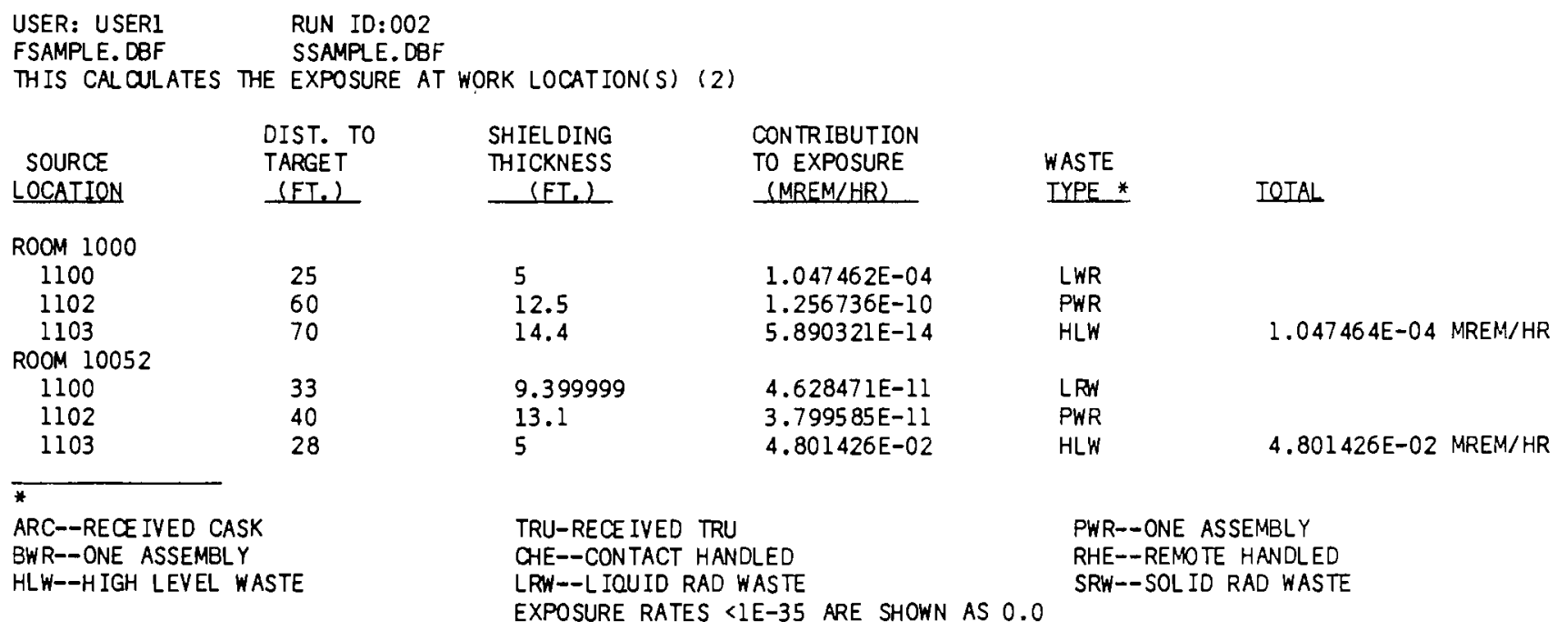

\section{EIGURE 3.2. Sample Specific Work Location}

Specific Source Location Analysis: Sample Facility

(Quantity of Mater1al in 1102 Increased 2X)

USER: USERI RUN ID:004

FSAMPLE. DBF SSAMPLE. DBF

THIS CAL CLLATES THE EXPOSURE DUE TO A SOURCE LOCATED IN 1102

TYPE OF MATERIAL: PWR NEW WEIGHT: 924 KG.

\begin{tabular}{|c|c|c|c|c|}
\hline $\begin{array}{c}\text { TARGET } \\
\text { LOCATION }\end{array}$ & $\begin{array}{l}\text { DIST. TO } \\
\text { TARGET } \\
\text { (EI, ) } \\
\end{array}$ & $\begin{array}{c}\text { SH IELDING } \\
\text { TH ICKNESS } \\
\text { (ET.) }\end{array}$ & $\begin{array}{l}\text { CONTRIBUTION } \\
\text { TO EXPOSURE } \\
\text { (MREM/HR) } \\
\end{array}$ & $\begin{array}{l}\text { WASTE } \\
\text { IYPE * }\end{array}$ \\
\hline $\begin{array}{l}1000 \\
1001 \\
1002 \\
1003 \\
1004 \\
10051 \\
10052\end{array}$ & $\begin{array}{l}60 \\
62 \\
70 \\
78 \\
15 \\
25 \\
40\end{array}$ & $\begin{array}{l}12.5 \\
13.1 \\
18.9 \\
24.7 \\
5 \\
5 \\
13.1\end{array}$ & $\begin{array}{l}2.513471 \mathrm{E}-10 \\
5.749886 \mathrm{E}-11 \\
1.100684 \mathrm{E}-16 \\
4.690235 \mathrm{E}-22 \\
3.378011 \\
2.432168 \\
7.59917 \mathrm{E}-11\end{array}$ & $\begin{array}{l}\text { PWR } \\
\text { PWR } \\
\text { PWR } \\
\text { PWR } \\
\text { PWR } \\
\text { PWR } \\
\text { PWK }\end{array}$ \\
\hline
\end{tabular}

* ARC--RECE IVED CASK

BWR--ONE ASSEMBLY

HLW--HIGH LEVEL WASTE
TRU-RECE IVED TRU

CHE--CONTACT HANDLED

LRW--LIOUID RAD WASTE

EXPOSURE RATES < IE-35 ARE SHOWN AS 0.0
PWR--ONE ASSEMBLY RHE--REMOTE HANDLED SRW-- SOL ID RAD WASTE

\section{EIGURE 3.3. Sample Specific Source Location}


Personnel Profile Analysis: Sample Facility

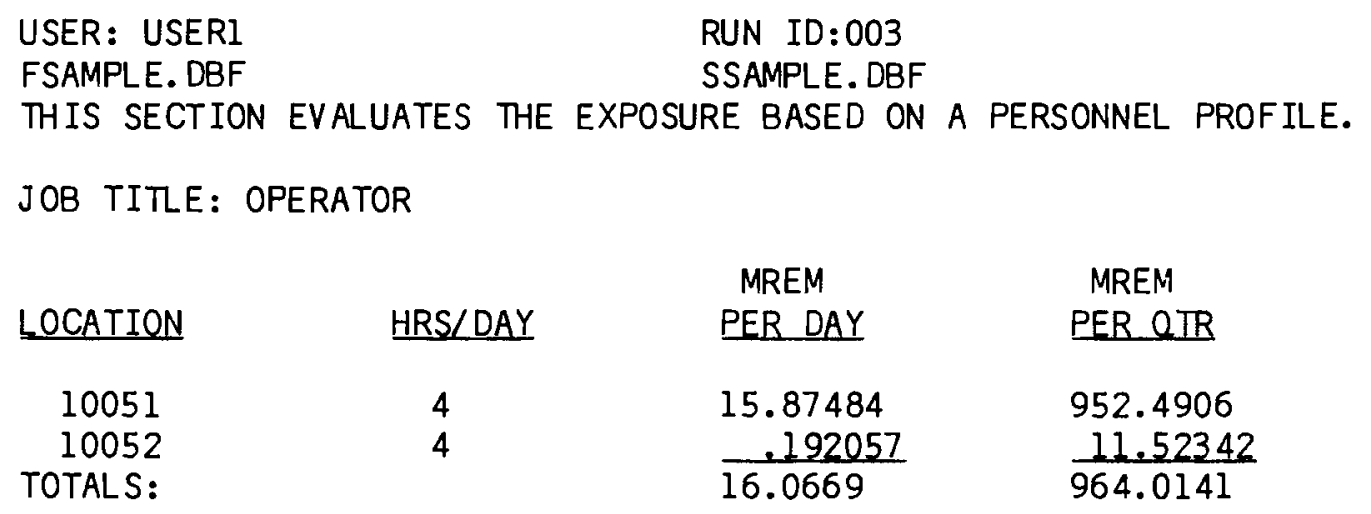

FIGURE 3.4. Sample Personnel Profile 


\subsection{APPLICATIONS OF EXCOMP}

When using EXCOMP as a design or licensing tool, an initial evaluation of the total facility should be performed. This evaluation may identify areas with exposure rates that may warrant a more detailed analysis. Only if the primary objective is the evaluation of the exposure to a particular personnel type, is the initial facility wide evaluation optional. The initial total facility evaluation creates a base case for the comparative analyses that are performed with each design change.

\subsection{DESIGN APPLICATION}

Following the creation of the facility and the source databases, an initial evaluation is made of the total facility (see Figure 4.1). The results of this evaluation are analyzed to determine if the exposure levels are acceptable, i.e., less than or equal to DOE requirements, at each work location. If the exposure rates are unacceptable in easily identified work locations the designer can perform the specific work location analysis, thereby reducing the length of computer processing time. However, if the exposure rates are high throughout the facility the designer should re-evaluate and/or modify the facility and perform a new analysis of the total facility.

Assuming that the facility has been designed to handle specific materials, the designer will need to determine where and what facility modifications are required. The designer, without adjusting the process operations, has two options available. The first option is to increase the shielding or distances at specific locations or throughout the facility. The second option is to use new construction materials. If the designer selects either of these options, the databases will need to be modified to reflect these changes. If the designer changes the shielding thickness the specific work location analysis can be used to evaluate the changes. If a different construction material is used the source database will need to be modified. If there will be isolated changes, i.e., a new material is used for the walls of each hot cell, the adjusted MeV value, for each source location, will need to be modified to reflect the new attenuation value. However, if a new material will be used throughout the facility, the source strength or adjusted MeV value will need 


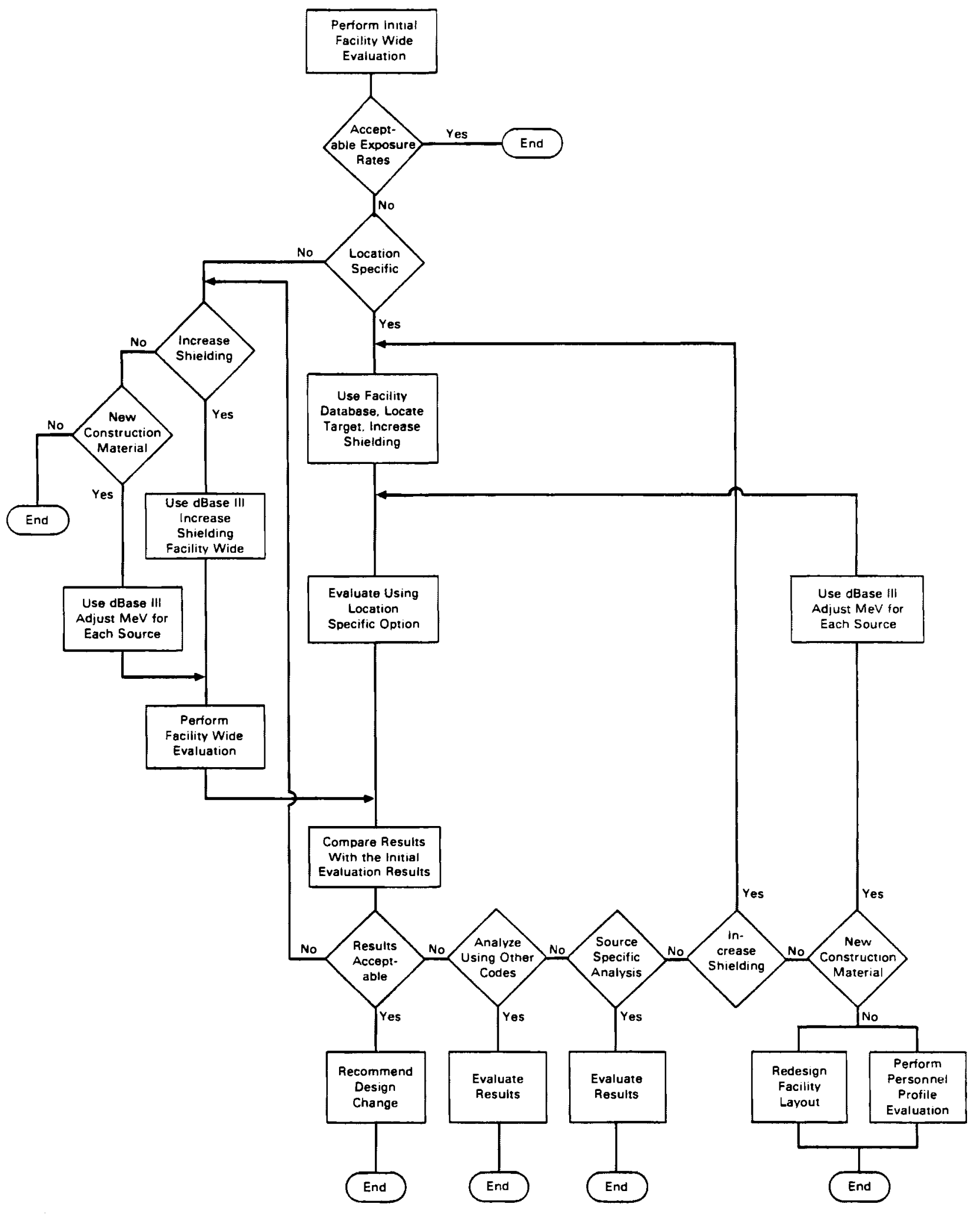

FIGURE 4.1. Design Applications of EXCOMP

4.2 
to be modified for all source locations to reflect the new attenuation value. For isolated changes in shielding material, the specific work location analysis can be used, reducing analysis time. If, after evaluating these changes, the exposure rates are still unacceptable the designer can repeat this process. However, after evaluating these modifications, the designer may decide to redesign the facility layout, perform a personnel profile analysis, or request a more detailed analysis of the facility using other more detailed analysis tools.

\subsection{LICENSING APPLICATION}

The licensing criteria for any facility is not based entirely on the exposure rates to the facility personnel or the public. However, exposure is a major consideration in granting an application for a license for a facility that handles radioactive materials. Therefore EXCOMP can be used to evaluate the exposure rates from a licensing agent's perspective (see Figure 4.2). If the licensing agent is unfamiliar with the exposure potential of a facility design, a facility-wide analysis can be performed to identify areas that may be of interest. EXCOMP can be used to further evaluate the exposure potential of these locations.

If the licensing agent has evaluated the facility using EXCOMP or has drawn some conclusions based on prior knowledge about the facility three options are available. The first option is to end the analysis and make recommendations, the second is to analyze specific locations in the facility, and the third is to investigate the exposure received by specific facility personnel. The results from the specific work location analysis or from the personnel profile analysis can be included in recommendations made by the agent. The results from each of these analyses can indicate areas requiring further investigations that can be performed using EXCOMP or other more detailed analysis tools.

It is important to note that the licensing agent's interests are not like those of the designer. The designer may modify the facility design and/or make recommendations regarding the proposed facility construction. The licensing agent is concerned about the established criteria regarding the exposure rates to the facility personnel and the public. 


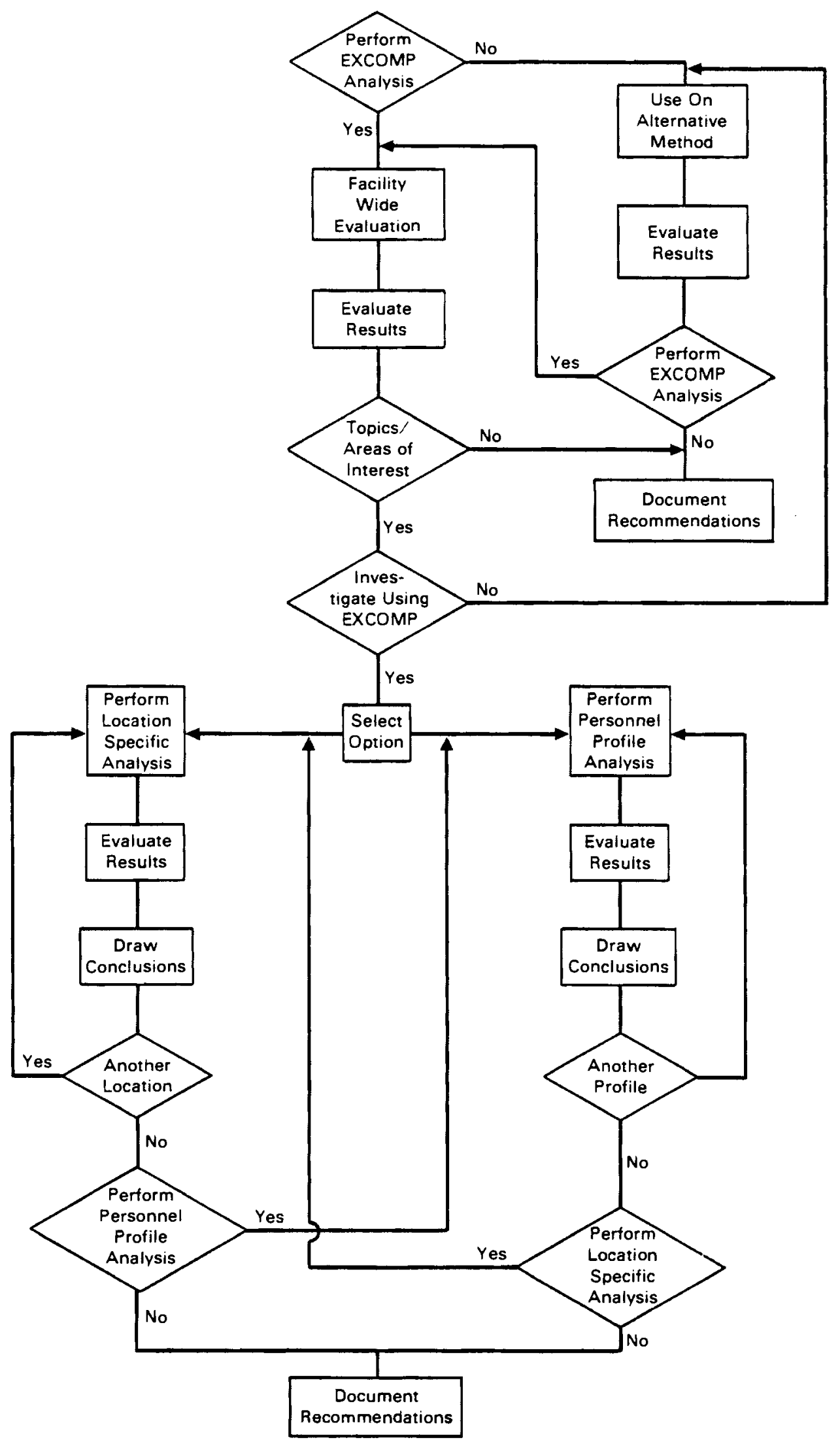

FIGURE 4.2. Licensing Applications of EXCOMP

4.4 


\subsection{PERSONNEL APPLICATIONS}

Management can use EXCOMP to determine personnel needs throughout the facility based on an employee's work location or the time an employee is at a specific work location. The personnel profile analysis requires the investigator to identify a personnel type and the average hours per day an employee will be at a specific work location (see Figure 4.3). The personnel profile analysis will project the daily and quarterly exposures received for each personnel type investigated. Using these projections, management can determine the personnel requirements and assignments to operate the facility within the required exposure limits. When evaluating the results derived from an EXCOMP analysis, management can identify specific work locations where high exposures are expected. With this information, management can perform a location specific analysis to confirm the results or request design changes to reduce personnel requirements.

Although each type of analysis will use the same database the results required by each are different. Designers can use EXCOMP to substantiate the proposed facility design or recommend or initiate design changes. Licensing agents can use EXCOMP to evaluate the exposures to facility personnel and the public to determine if the criteria regarding exposure limits have been satisfied. If the criteria have not been satisfied, design recommendations, based on EXCOMP results, can be forwarded to the designer. Management can use EXCOMP to predict exposures to specific personnel and can also provide the designer with the information necessary to initiate design changes to reduce the need for personnel.

\subsection{COMPARATIVE ANALYSES}

The design, licensing and personnel applications all can use ExCOMP to perform a comparative analysis. When performing a comparative analysis it is important that only those elements that the user wants to modify be changed. EXCOMP operates on this basic principle if the proposed change is a facility modification, the characteristics and assumptions used to describe the source are not changed. 


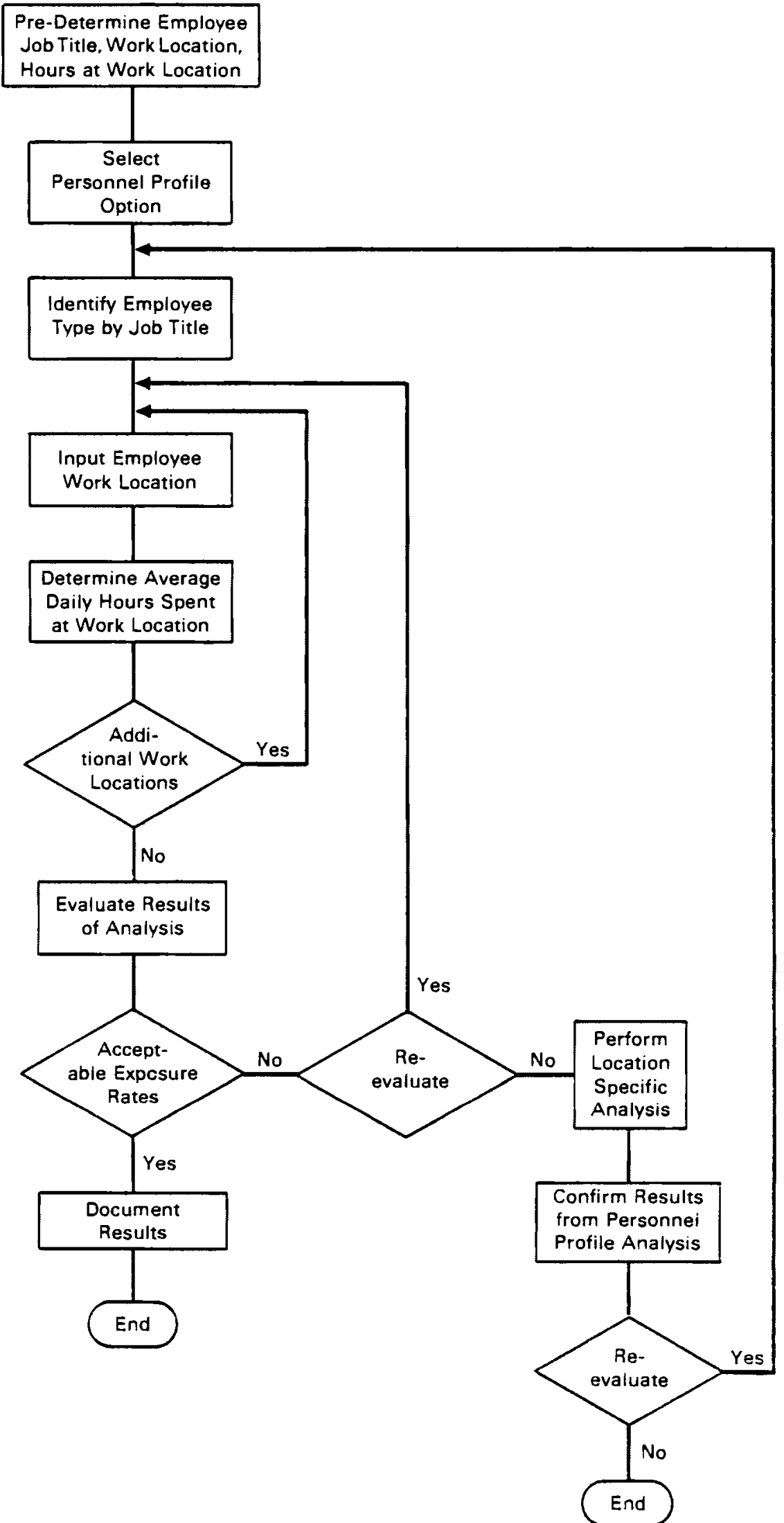

FIGURE 4.3 Personnel Applications of EXCOMP 
The comparative analysis can be used by the designer and management before changing the facility design or operation. As each investigator determines some change is appropriate a new EXCOMP analysis can be performed. The results from these analyses can be compared to the first or original analysis to determine the changes in exposure rates. When analyses are performed before facility construction, they can later reduce costs if the completed facility has to be modified or if new personnel are added to operate the facility. 



\subsection{PROGRAM DESCRIPTION}

The interpreter in EXCOMP is a computer program that interfaces with two databases and extracts the information required to perform an exposure analysis (see Figure 2.1). Given a user specified work location, EXCOMP will search the source database until the source location(s) corresponding to the work location is found. The main program, referred to as the interpreter module, controls the database searches and calculates the exposure rates at various locations throughout the facility. The user sets the parameters controlling the search, based on the option selected. The options available are a total facility analysis, a specific work location analysis, a specific source location analysis, and a particular personnel profile analysis. The methods used to calculate the exposure rates for each of these options are basically the same. However, the total facility, specific work location and specific source location analyses predict the exposure rate per hour to facility personnel, and the personnel profile option projects the exposure per day and sums these values, based on work locations, to project a quarterly exposure rate.

When the source location has been found, the interpreter projects the exposure rate for that location. The calculations are based on the source's characteristics, the distance the source is from the work location and the amount of shielding separating the source from the work location. The source is characterized based on the type of material, energy levels, quantity, and the attenuation of the shielding. The distances are calculated in feet as are the shielding thicknesses. The databases used to characterize the work location and the sources will be described in the following section.

\subsection{PROGRAM EXECUTION}

EXCOMP will prompt the user for the type of analysis to be performed (see Figure 5.1). If the user selects the facility wide option no further inputs are required. If the user selects the option to evaluate the exposure at a specific work location, the user will be required to identify that location. If the user selects the personnel profile option the user will be required to enter the person's job title, the work location in question and the average length of time per day the employee is at that location. 


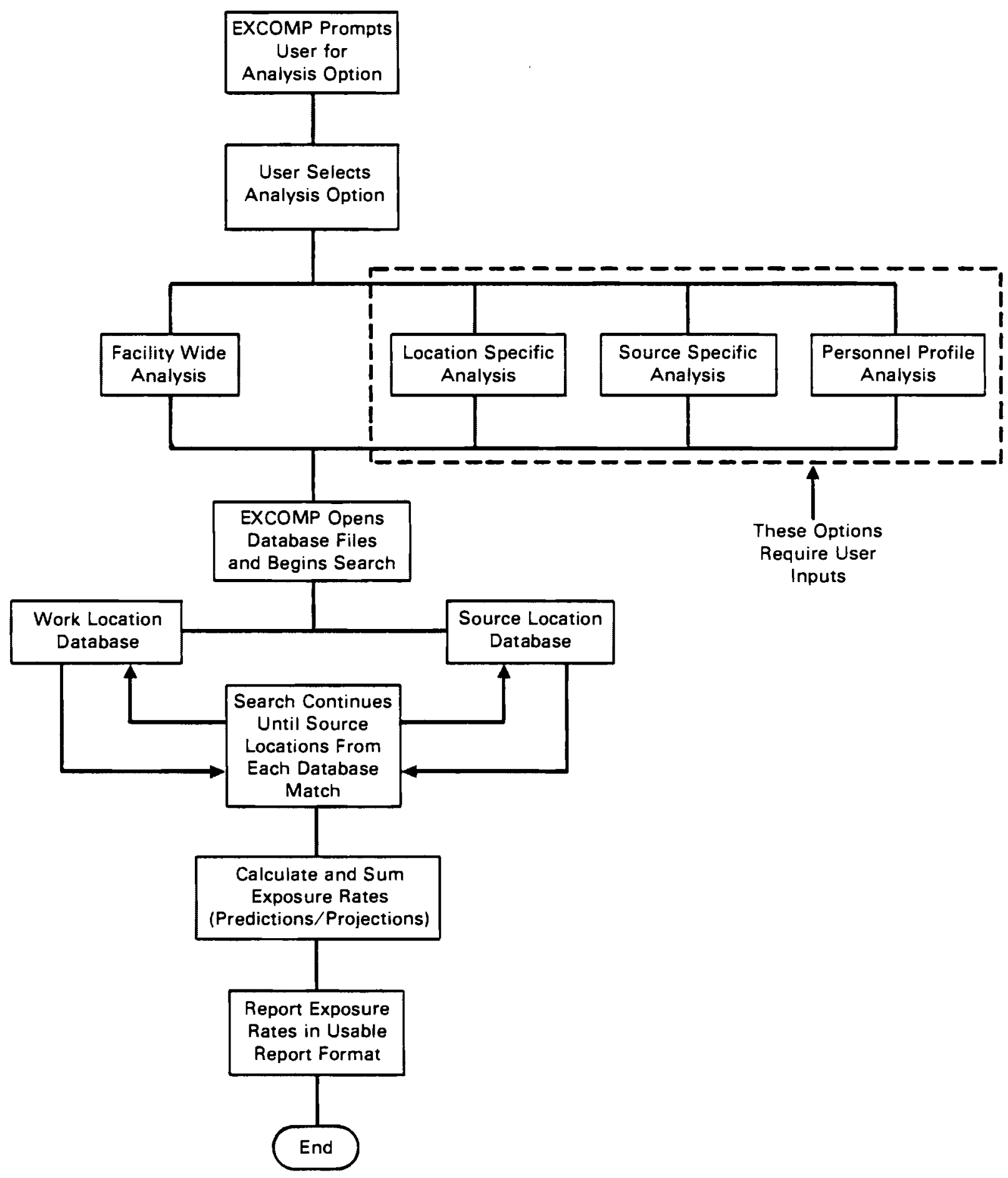

FIGURE 5.1. Program Description 


\subsection{DATABASE STRUCTURE}

This program is designed to evaluate the effects any changes may have on personnel exposures from radioactive materials with respect to ALARA. There are two database files external to the program, one file characterizes the facility and the other file characterizes the source. The facility database identifies the work locations. The selection of the work locations or targets should be performed using the facility layout drawings in conjunction with a facility process description.

The work or target locations for the MRS, are defined, as those locations frequented by the facility personnel that do not involve contact handling of radioactive materials or packages. This will include the management and support offices and the operating corridors. This will not include any decon room, storage room, or radwaste handling rooms. These rooms were not included for the following two reasons: The non-radioactive storage rooms are used intermittently by the facility personnel and are not normally occupied daily; and any room involving the handling of radioactive material will be closely monitored by the onsite health physicist. However, this does not preclude these rooms from further analyses.

The difficulty in selecting a work location is in determining where an employee's work station is located in any one room and upon closer inspection of the office wing it will be even more difficult to predict the movements of the office staff. Therefore, a central location in each room, or in the office wing was identified as the work station for that particular work location (see Figure 5.2).

The source locations are defined for the MRS, as those locations where radioactive materials are stored, handled, processed, received/transported, or where contaminated equipment is decontaminated or stored. The same difficulty encountered in selecting the work location is encountered when identifying a source's exact location in a room.

The example facility is assumed to operate continuously; therefore, only those areas identified on the facility layout drawings as lag storage areas, have clearly defined source locations. Therefore,like the work locations, 
the source locations are assumed to be in the central region of each room (see Figure 5.2). This assumption will create some error in the exposure predictions; however, if the same assumption is used throughout all analyses any comparative analyses performed will be valid.

The following paragraphs refer to the sample facility drawing (see Figure 5.1) and describe each of the following six fields created in the facility characterization database. The database was created with six fields, they are: 1) TARGET; 2) SOURCE; 3)DIST_FT; 4)BARRIERA; 5)BARRIERB; and 6) BARRIERC. The structure of these databases are not rigid and can be changed to suit the users needs.

TARGET--This is the work location. The work locations or targets are identified in the example drawing with a "T". When characterizing this example, the center of an office and/or the mid-point of a corridor is selected as the target location. These target locations are selected based on probable employee work stations. If the work stations have been identified, these should be used as the target locations.

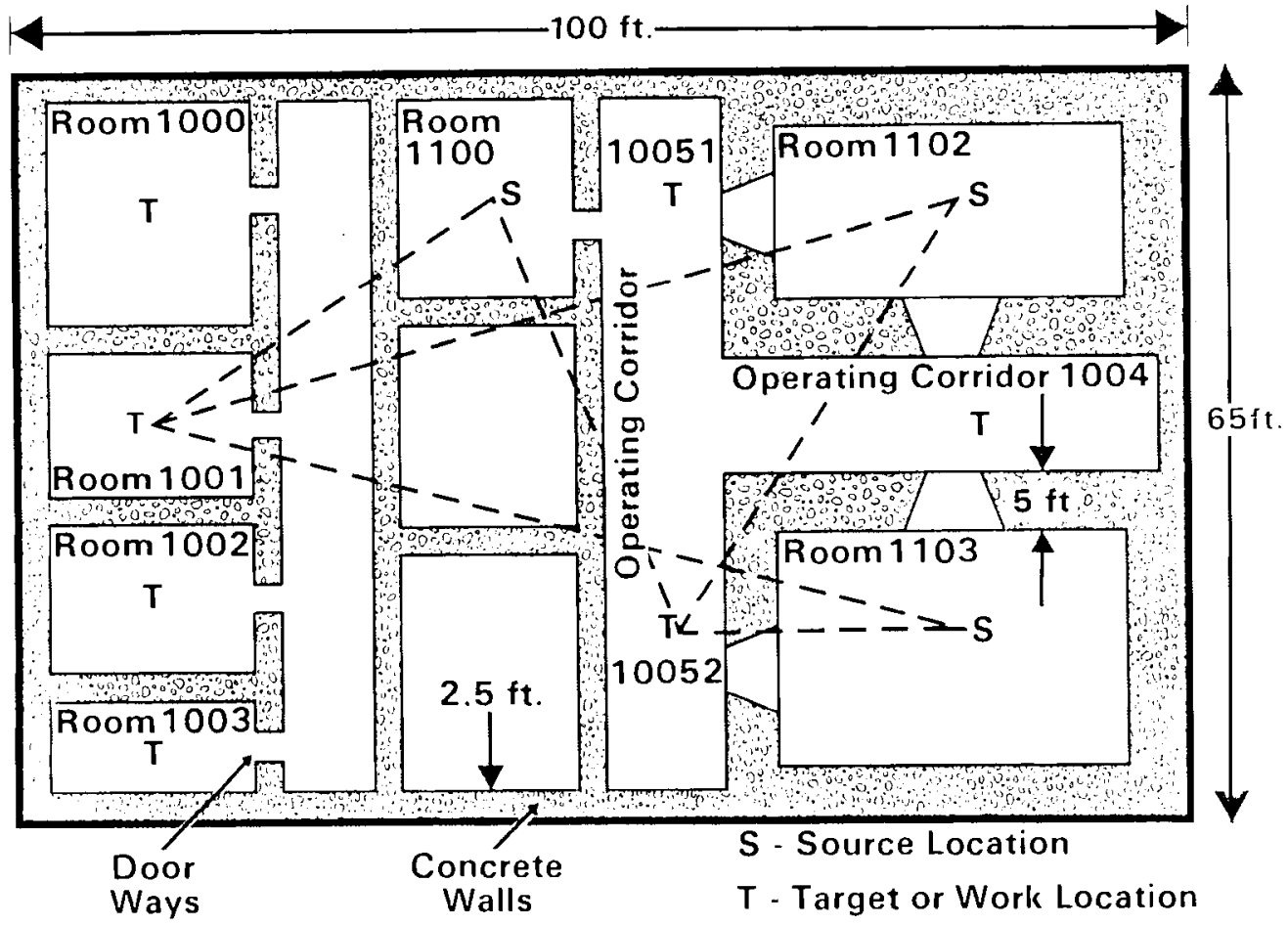

FIGURE 5.2. Example Facility Layout 
SOURCE--This is the location of each source that contributes to the exposure received by an employee at the identified target location. These source locations are identified with an "S" on the example drawing. The source location in a continuous operation is unpredictable. Therefore, unless strong justifications can be shown otherwise, the center of each room should be selected as the source location.

DIST_FT--This is the straight line distance from the target location (T) to the source location (S).

BARRIERA--This is the sum of the shielding encountered in a straight line from the target to the source location. In this example, BarrierA refers to the sum of the perpendicular or slant thicknesses of the concrete walls $(2.35 \mathrm{~g} / \mathrm{cc})$. BARRIERB--This is the sum of the perpendicular or slant thicknesses of the steel walls encountered in a straight line from the target to the source location. BARRIERC--This is used to if the user increases the thickness of the shielding or if the user wants to determine the effects on exposure rates if another shielding material is used. Currently, EXCOMP assumes that the shielding identified in Barrierc is concrete. If the user wants to use some other material, i.e. lead, plastic, aluminum, etc., it will be necessary to modify the existing code. This requires the user to enter the linear attenuation coefficients of the new material based on the source's energy levels.

The second database characterizes the sources. The sources in this facility are assumed to be radioactive and can occur in various forms. Each of the process and in-process-storage locations should be considered source locations. The following descriptions describe each of the six fields created in the source characterization database to characterize the sources in the example facility (see Figure 5.1). The database fields used to identify and characterize the sources and their locations are: 1)SOURC; 2)MU1; 3)MU2; 4)MU3; 5)MU4; 6) TYPE; and 7) QUANTITY.

SOURCE--This is the location of the source, and is identified in the example with an "S". As stated previously in the Target database the exact location of the source is difficult to predict; therefore, unless specified otherwise, the center of the room should be used as the source location. These sources are the same sources identified in the facility database. 
MU1, MU2, MU3, and MU4--These data base fields should be used to describe the source based on the energy groupings described in Appendix $B$. Because this example facility handles radioactive materials, these data base fields would contain the energy levels based on the type of radioactive materials present in the facility.

TYPE--This refers to the types of materials handled at the source locations, i.e. PWR, BWR, etc., and is not used in the calculations. This only appears in the output for information purposes.

QUANTITY--This database field represents the quantity of material found at each location. The source strengths and the release rates are based on one metric ton initial heavy metal (MTIHM). Based on the material type and normal operating conditions different quantities of material can be handled or processed at each source location. Therefore, this value is used to adjust the release rates based on the quantity of material normally handled at the source location. 
APPENDIX A

CHARACTERIZING THE FACILITY 



\section{APPENDIX A}

\section{CHARACTERIZING THE FACILITY}

\section{A.1. CALCULATING THE DISTANCE FROM THE WORK TO THE SOURCE LOCATION}

If only a single level is to be analyzed, the distance is a straight line path from the work location to the source location (see Figure 5.2), this method will represent shortest distance. However, if the work location and the source location are not on the same floor and not in a direct path, above or below, the distance is the shortest calculated distance.

\section{A.2 CHARACTERIZING THE BARRIERS}

Characterizing the barriers or shielding involves calculating the perpendicular thickness of the shielding and identifying the shielding construction materials. This work can be performed concurrently with calculating the distance from the work location to the source location. Referring to Figure 5.2, the line used to calculate the distance intersects a number of walls that comprise the shielding. The energy emitted from the source will penetrate the shielding and a portion of this energy will be absorbed by the shielding. The amount of energy absorbed is dependent on the shielding construction, the material used and its thickness. The material used to construct the shield will determine the rate at which the energy is absorbed. This rate is the attenuation factor for the particular shielding material (for a further discussion see Appendix B).

As the shielding increases in thickness the amount of energy absorbed will increase; therefore, the horizontal and vertical thicknesses were summed and adjusted to reflect the slant thickness. The program used to calculate the shielding thickness is as follows: 


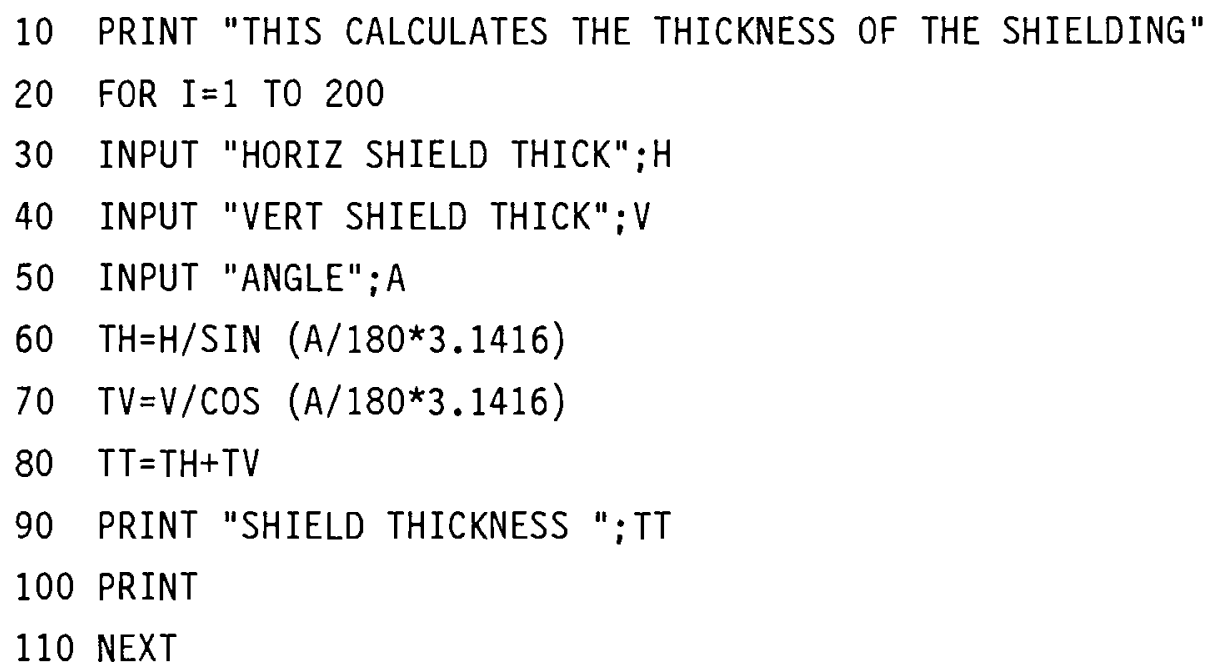


APPENDIX B

CHARACTERIZING THE SOURCE 


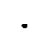


APPENDIX B

\section{CHARACTERIZING THE SOURCE}

In the MRS Facility the majority of the materials processed will fall into three catagories: 1. PWR Spent Fuel; 2. BWR Spent Fuel; and 3. HighLevel Wastes and/or TRU, and the processing operations will generate low-level and high-level wastes. Essentially, each of these waste forms are composed of the same material; however, the energy levels and the quantity of material present will differ.

In this facility the source geometry changes with each operation. To reduce the errors that may be encountered when selecting the proper geometry a constant geometry was used throughout the facility analysis. For this analysis the source was assumed to be a culminating beam and was evaluated similar to the point source, i.e. the resultant was divided by the distance squared (see Appendix C).

Identifying the source is performed concurrently with identifying the source locations. It is possible from the facility layout to determine what the source is at each location. The room identification, supplied by the designer, may indicate what the source is, i.e., Room \#1053 Solid Radwaste, etc. It is also necessary to examine the available documents describing the facility operations to determine if some process paths are dedicated to a specific source type.

There is available, from previous unrelated evaluations, information regarding the composition of spent fuel. However, there is virtually no information regarding the other forms of waste to be processed. The difficulty arises when characterizing and determining the quantity of material of these other waste forms. Therefore, all materials to be processed in the facility will be characterized on the basis of the ORIGEN2 runs for PWR and BWR Spent Fuel. 


\section{B.1. ORIGEN2 ANALYSIS OF PWR SPENT FUEL}

The results of the ORIGEN2 (Croff et al. 1978) analysis for PWR Spent Fuel was used as the basis for all PWR sources identified. The ORIGEN2 analysis was based on: 4.4-W/0 Enrichment; 55-GWD/MT Burnup; and a 10-year period since discharge. The assumptions used in the analysis were based on the data presented in Table B.1.

TABLE B.1. Photon Spectrum for PWR Spent Fuel

\begin{tabular}{|c|c|c|c|c|}
\hline $\begin{array}{l}\text { EMEAN } \\
(\mathrm{MeV})\end{array}$ & $\begin{array}{l}\text { Activation } \\
\text { Products } \\
\text { (photons } / \text { sec) } \\
\end{array}$ & $\begin{array}{c}\text { Actinides + } \\
\text { Daughters } \\
\text { (photons/sec) }\end{array}$ & $\begin{array}{c}\text { Fission } \\
\text { Products } \\
\text { (photons/sec }\end{array}$ & \\
\hline $\begin{array}{l}1.50 \mathrm{E}-2 \\
2.50 \mathrm{E}-2 \\
3.75 \mathrm{E}-2 \\
5.75 \mathrm{E}-2 \\
8.50 \mathrm{E}-2 \\
1.25 \mathrm{E}-1 \\
2.25 \mathrm{E}-1 \\
3.75 \mathrm{E}-1\end{array}$ & $\begin{array}{l}8.85 \mathrm{E}+12 \\
5.87 \mathrm{E}+12 \\
1.95 \mathrm{E}+12 \\
9.33 \mathrm{E}+11 \\
3.69 \mathrm{E}+11 \\
1.70 \mathrm{E}+11 \\
4.47 \mathrm{E}+11 \\
2.40 \mathrm{E}+12\end{array}$ & $\begin{array}{l}1.07 \mathrm{E}+14 \\
2.46 \mathrm{E}+12 \\
5.31 \mathrm{E}+11 \\
3.57 \mathrm{E}+13 \\
1.86 \mathrm{E}+12 \\
1.60 \mathrm{E}+12 \\
1.28 \mathrm{E}+12 \\
7.47 \mathrm{E}+10\end{array}$ & $\begin{array}{l}2.94 \mathrm{E}+15 \\
6.36 \mathrm{E}+14 \\
8.11 \mathrm{E}+14 \\
5.69 \mathrm{E}+14 \\
3.61 \mathrm{E}+14 \\
3.68 \mathrm{E}+14 \\
2.95 \mathrm{E}+14 \\
1.37 \mathrm{E}+14\end{array}$ & \\
\hline $\begin{array}{l}5.75 E-1 \\
8.50 E-1 \\
1.25 E+0\end{array}$ & $\begin{array}{l}3.07 E+12 \\
1.81 E+11 \\
3.03 E+14\end{array}$ & $\begin{array}{l}2.17 E+09 \\
3.21 E+09 \\
1.34 E+09\end{array}$ & $\begin{array}{l}5.46 E+15 \\
5.44 E+14 \\
2.15 E+14\end{array}$ & $j$ \\
\hline $\begin{array}{l}1.75 E+0 \\
2.25 E+0 \\
2.75 E+0\end{array}$ & $\begin{array}{l}4.95 E+07 \\
1.61 E+09 \\
4.97 E+06\end{array}$ & $\begin{array}{l}4.12 E+08 \\
1.82 E+08 \\
9.82 E+08\end{array}$ & $\begin{array}{l}6.10 \mathrm{E}+12 \\
7.93 \mathrm{E}+10 \\
5.66 \mathrm{E}+09\end{array}$ & $j$ \\
\hline $3.50 E+0$ & $1.11 E+02$ & $9.49 E+07$ & $7.35 \mathrm{E}+08$ & \\
\hline $\begin{array}{l}5.00 E+0 \\
7.00 E+0 \\
1.10 E+1\end{array}$ & $\begin{array}{l}5.17 \mathrm{E}-08 \\
3.35 \mathrm{E}-09 \\
2.12 \mathrm{E}-10 \\
\end{array}$ & $\begin{array}{l}4.06 \mathrm{E}+07 \\
4.68 \mathrm{E}+06 \\
5.38 \mathrm{E}+05 \\
\end{array}$ & $\begin{array}{l}9.67 \mathrm{E}-05 \\
6.27 \mathrm{E}-06 \\
3.97 \mathrm{E}-07 \\
\end{array}$ & $j$ \\
\hline TOTAL & $3.27 E+14$ & $1.51 E+14$ & $1.20 E+16$ & \\
\hline
\end{tabular}

(a) Only these sections were used in the analysis.

As noted, only selected areas of the photon spectrum were used to characterize a PWR source. The selections were based on the expected shielding thicknesses and on conversations with an expert in shielding calculations. The very low-and very high-energy level photons, i.e., MeV $\langle 1.0$ and MeV $>3.5$, were, 
in the opinion of the expert, of no consequence. The expert's opinion was based on previous results when examining exposures due to spent fuel shipping casks. In the opinion of the expert, any shielding in the MRS Facility would be sufficient to shield the large quantities of the very low-level photons. It was also the opinion of the expert that very high-level photons would not contribute significantly to the exposure rate.

A method for photon grouping was devised to reduce the size of the database and to include the very high - and low-level photons. This method was based on a weighted average system. An example follows using the activation products in the range of 1.25 to $1.75 \mathrm{MeV}$ :

\begin{tabular}{|c|c|c|c|c|}
\hline $\begin{array}{l}\mathrm{MeV} \\
\mathrm{MeV}\end{array}$ & $\begin{array}{l}\text { Photons / } \\
\text { second }\end{array}$ & $\begin{array}{c}\text { Total Photons/ } \\
\text { second }\end{array}$ & $\begin{array}{l}\% \text { of } \\
\text { Total }\end{array}$ & $\begin{array}{l}\text { Weighted } \\
\text { Average MeV }\end{array}$ \\
\hline $\begin{array}{l}1.25 \\
1.75\end{array}$ & $\begin{array}{l}3.03 E+14 \\
4.95 E+07\end{array}$ & $3.03 E+14$ & $\begin{array}{l}>99 \% \\
<1 \%\end{array}$ & $\begin{aligned}(\mathrm{MeV}= & {[.99 \times 1.25]+} \\
& {[.01 \times 1.75]) }\end{aligned}$ \\
\hline
\end{tabular}

The weighted average MeV was calculated for the Actinides + Daughters and the Fission Products in this manner. A summary table lists the weighted average $\mathrm{MeV}$ and the average MeV for each decay product. The average MeV, column five, is used in the analysis to characterize the PWR source and to determine the effects of concrete as a shielding material.

\begin{tabular}{|c|c|c|c|c|}
\hline $\begin{array}{l}\text { MeV } \\
\text { Range } \\
\end{array}$ & $\begin{array}{l}\text { Fission } \\
\text { Products }\end{array}$ & $\begin{array}{l}\text { Actinides+ } \\
\text { Daughters }\end{array}$ & $\begin{array}{l}\text { Activation } \\
\text { Products }\end{array}$ & $\begin{array}{c}\text { Average } \\
\mathrm{MeV}\end{array}$ \\
\hline $\begin{array}{l}0.575-1.25 \\
1.75-2.75 \\
3.5 \\
5.00-11.0\end{array}$ & $\begin{array}{l}0.62 \\
1.76 \\
3.5 \\
5.16\end{array}$ & $\begin{array}{l}0.84 \\
2.43 \\
3.5 \\
5.26\end{array}$ & $\begin{array}{l}1.24 \\
2.24 \\
3.5 \\
5.12\end{array}$ & $\begin{array}{l}0.9 \\
2.1 \\
3.5 \\
5.2\end{array}$ \\
\hline
\end{tabular}

\section{B.2. ORIGEN2 ANALYSIS OF BWR SPENT FUEL}

The results of the ORIGEN2 (Croff et al. 1978) analysis for BWR Spent Fuel was used as the basis for all BWR sources identified. The ORIGEN2 analysis was based on: 3.6 W-0 Enrichment; 48-GWD/MT Burnup; and a 10-year discharge. The assumptions used in the analysis were based on the data presented in Table B.2. 
TABLE B.2. Photon Spectrum for BWR Spent Fuel

EMEAN

(MeV)

1.50E-2

2.50E-2

$3.75 \mathrm{E}-2$

$5.75 \mathrm{E}-2$

8.50E-2

1. $25 \mathrm{E}-1$

2. $25 \mathrm{E}-1$

3. $75 \mathrm{E}-1$

5.75E-1

8.50E-1

1. $25 \mathrm{E}+0$

$1.75 \mathrm{E}+0$

$2.25 E+0$

$2.75 \mathrm{E}+0$

$3.50 E+0$

5.00E+0

7. $00 \mathrm{E}+0$

1. $10 \mathrm{E}+1$

TOTAL

\begin{tabular}{ccc} 
& Photon Spectrum \\
\hline Activation & Actinides + & Fission \\
Products & Daughters & Products \\
(photons $/$ sec) & (photons $/$ sec) & (photons $/$ sec)
\end{tabular}

$4.04 \mathrm{E}+12$

$5.61 \mathrm{E}+12$

$1.63 \mathrm{E}+12$

4.09E+11

1. $64 \mathrm{E}+11$

9. $39 \mathrm{E}+10$

4. $72 \mathrm{E}+11$

$2.70 \mathrm{E}+12$

\section{3. $46 \mathrm{E}+12$}

6. $37 \mathrm{E}+10$

1. $24 \mathrm{E}+14$

$4.56 \mathrm{E}+07$

$6.58 \mathrm{E}+08$

$2.04 E+06$

$9.54 \mathrm{E}+13$

2. $21 \mathrm{E}+12$

$4.83 \mathrm{E}+11$

3. $20 \mathrm{E}+13$

1. $74 \mathrm{E}+12$

$1.47 \mathrm{E}+12$

1. $16 \mathrm{E}+12$

7. $00 \mathrm{E}+10$

1. $69 \mathrm{E}+09$

2. $92 \mathrm{E}+09$

1. $31 \mathrm{E}+09$

$3.43 \mathrm{E}+08$

1. $62 \mathrm{E}+08$

$6.23 \mathrm{E}+08$

$2.83 E-02$

5.19E-08

3. $36 \mathrm{E}-09$

2.13E-10

$8.42 E+07$

3. $60 E+07$

4. $16 \mathrm{E}+06$

$4.77 \mathrm{E}+05$

$1.43 E+14$

$1.35 E+14$
$2.46 \mathrm{E}+15$

5. $27 \mathrm{E}+14$

$6.82 \mathrm{E}+14$

$4.75 \mathrm{E}+14$

3. $00 E+14$

3. $08 \mathrm{E}+14$

2. $46 \mathrm{E}+14$

1. $12 \mathrm{E}+14$

$4.59 E+15$ )

$4.13 \mathrm{E}+14>(\mathrm{a})$

$1.79 E+14$ J

$5.16 E+12)$

$5.31 E+10$ > (a)

$4.05 E+09$ )

$5.26 E+08 \quad(a)$

8.52E-05 )

$5.53 \mathrm{E}-06>(\mathrm{a})$

3.50E-07

$1.03 E+16$

(a) Only these sections were used in the analysis.

The same approach, described earlier, was used when determining the photon groupings in the BWR analysis. The summary table for the decay product follows. The averages in column five are used for the BWR source characterizations.

\begin{tabular}{|c|c|c|c|c|}
\hline $\begin{array}{l}\text { MeV } \\
\text { Range }\end{array}$ & $\begin{array}{l}\text { Fission } \\
\text { Products }\end{array}$ & $\begin{array}{l}\text { Actinidest } \\
\text { Daughters }\end{array}$ & $\begin{array}{l}\text { Activation } \\
\text { Products }\end{array}$ & $\begin{array}{c}\text { Average } \\
\mathrm{MeV}\end{array}$ \\
\hline $\begin{array}{l}0.575-1.25 \\
1.75-2.75 \\
3.5 \\
5.00-11.0\end{array}$ & $\begin{array}{l}0.62 \\
1.76 \\
3.5 \\
5.16\end{array}$ & $\begin{array}{l}0.86 \\
2.35 \\
3.5 \\
5.26\end{array}$ & $\begin{array}{l}1.23 \\
2.21 \\
3.5 \\
5.12\end{array}$ & $\begin{array}{l}0.9 \\
2.1 \\
3.5 \\
5.2\end{array}$ \\
\hline
\end{tabular}


It is noteworthy, that the MeV averages for the BWR are similar to the PWR MeV averages. Therefore, it will be assumed that all spent fuel received, with the identical compositions and burnup rates as those used in the ORIGEN2 analyses, have similar energy levels. This implies that wastes generated in the facility have the same energy levels; although, the quantity to be analyzed will be smaller.

\section{B. 3 ANALYSIS OF OTHER SOURCES}

It is assumed that the other radioactive material encountered in the MRS facility will be comprised of PWR and BWR products. Therefore, the same weighted average MeV values will be used for those sources identified as HLW (high-level waste), SRW (solid rad waste), LRW (liquid rad waste), TRU (trans-uranic waste), CHE (contact-handled waste or equipment), and RHE (remotehandled waste or equipment).

The weight or quantity of material present at each source location is reduced to reflect lower concentrations. These reductions are based on engineering judgment or actual data if it is available. These reductions are necessary to evaluate each of the source's exposure potential, i.e. the less material present the less exposure potential. The photon spectrum for these sources are determined by averaging the photon release rates for PWR and BWR spent fuel.

\section{B.4 RESULTS OF THE ANALYSES}

The results of the analyses described in Sections B.1, B.2 and B.3 are used to determine the linear attenuation coefficients for the shielding materials, the photon energy flux to biological dose-rate factors and the buildup factors. These values are then combined with the intensities and the quantity of material present to calculate the dose rate.

The linear attenuation coefficients used in EXCOMP are interpolated values based on the following table (Glasstone and Sesonske 1981). As stated in the database description EXCOMP initially includes the linear attenuation coeffificients for concrete and steel. 
Table B.3. Linear Attenuation Coefficients in $\mathrm{M}^{-1}$ Units $(\mathrm{a})$

\begin{tabular}{|c|c|c|c|c|c|}
\hline $\begin{array}{c}\text { Energy } \\
\mathrm{MeV}\end{array}$ & Water & Concrete & Aluminum & Iron & Lead \\
\hline 0.5 & 9.66 & 20.0 & 22.7 & 65.1 & 164 \\
\hline 1.0 & 7.06 & 14.9 & 16.6 & 46.8 & 77.6 \\
\hline 1.5 & 5.75 & 12.1 & 13.5 & 38.1 & 58.1 \\
\hline 2.0 & 4.93 & 10.5 & 11.7 & 33.3 & 51.8 \\
\hline 3.0 & 3.96 & 8.53 & 9.53 & 28.4 & 47.7 \\
\hline 4.0 & 3.39 & 7.45 & 8.37 & 25.9 & 47.6 \\
\hline 5.0 & 3.01 & 6.74 & 7.61 & 24.6 & 48.3 \\
\hline 8.0 & 2.40 & 5.71 & 6.51 & 23.2 & 52.0 \\
\hline 10.0 & 2.19 & 5.38 & 6.18 & 23.1 & 55.4 \\
\hline
\end{tabular}
(a) Prior to the adoption of SI units, linear attenuation coefficients were reported in $\mathrm{Cm}^{-1}$ units; the latter values are 0.01 times those in Table B.3.

The buildup factors used in EXCOMP are based on the calculated $\mu x$ value which is based on the shielding thickness and the linear attenuation coefficiant for the shielding material. The value $\mu \mathrm{x}$ is calculated in ExCOMP and the buildup factor is interpolated based on interpolated values derived from table B. 4 .

Table B.4. Gamma-Ray Exposure Buildup Factors for a Point Isotropic Source

\begin{tabular}{|c|c|c|c|c|c|c|c|c|c|}
\hline \multirow[b]{2}{*}{ Material } & \multirow{2}{*}{$\begin{array}{c}\text { Energy, } \\
\mathrm{MeV} \\
\end{array}$} & \multicolumn{7}{|c|}{$\mu x$} & \multirow[b]{2}{*}{20.00} \\
\hline & & $\underline{0.50}$ & $\underline{1.00}$ & 2.00 & 4.00 & 7.00 & 10.00 & 15.00 & \\
\hline Water [7]. & $\begin{array}{r}0.5 \\
1.0 \\
2.0 \\
5.0 \\
10.0\end{array}$ & $\begin{array}{l}1.60 \\
1.47 \\
1.38 \\
1.29 \\
1.21\end{array}$ & $\begin{array}{l}2.44 \\
2.08 \\
1.83 \\
1.57 \\
1.39\end{array}$ & $\begin{array}{l}4.84 \\
3.60 \\
2.81 \\
2.10 \\
1.70\end{array}$ & $\begin{array}{c}12.6 \\
7.63 \\
4.98 \\
3.12 \\
2.28\end{array}$ & $\begin{array}{r}31.9 \\
15.6 \\
8.63 \\
4.64 \\
3.13\end{array}$ & $\begin{array}{c}61.2 \\
25.8 \\
12.7 \\
6.15 \\
4.64\end{array}$ & $\begin{array}{c}135 \\
47 \\
20 \\
8.6 \\
6.15\end{array}$ & $\begin{array}{c}243 \\
73 \\
28 \\
11 \\
8.6\end{array}$ \\
\hline $\begin{array}{c}\text { Concrete }[7] \\
(\text { Density } \\
\left.2.53 \mathrm{Mg} / \mathrm{m}^{3}\right)\end{array}$ & $\begin{array}{r}0.5 \\
1.0 \\
2.0 \\
4.0 \\
6.0 \\
10.0\end{array}$ & $\begin{array}{l}1.57 \\
1.45 \\
1.37 \\
1.30 \\
1.26 \\
1.20\end{array}$ & $\begin{array}{l}2.27 \\
1.98 \\
1.78 \\
1.60 \\
1.49 \\
1.36\end{array}$ & $\begin{array}{l}4.04 \\
3.25 \\
2.66 \\
2.19 \\
1.93 \\
1.65\end{array}$ & $\begin{array}{l}9.02 \\
6.45 \\
4.63 \\
3.37 \\
2.80 \\
2.22\end{array}$ & $\begin{array}{r}20.3 \\
12.8 \\
8.00 \\
5.25 \\
4.15 \\
3.12\end{array}$ & $\begin{array}{c}36.7 \\
20.8 \\
11.7 \\
7.21 \\
5.53 \\
4.04\end{array}$ & $\begin{array}{c}76.2 \\
37.3 \\
18.6 \\
10.6 \\
7.88 \\
5.65\end{array}$ & $\begin{array}{c}132 \\
57.1 \\
26.1 \\
14.1 \\
10.3 \\
7.32\end{array}$ \\
\hline Iron [8] & $\begin{array}{l}0.5 \\
1.0 \\
2.0 \\
3.0\end{array}$ & $\begin{array}{l}-- \\
-- \\
--\end{array}$ & $\begin{array}{l}1.98 \\
1.87 \\
1.76 \\
1.55\end{array}$ & $\begin{array}{l}3.09 \\
2.89 \\
2.43 \\
2.15\end{array}$ & $\begin{array}{l}5.98 \\
5.59 \\
4.13 \\
3.51\end{array}$ & $\begin{array}{c}11.7 \\
10.2 \\
7.25 \\
5.85\end{array}$ & $\begin{array}{c}19.2 \\
16.2 \\
10.9 \\
8.51\end{array}$ & $\begin{array}{l}35.4 \\
28.3 \\
17.6 \\
13.5\end{array}$ & $\begin{array}{l}55.6 \\
42.7 \\
25.1 \\
19.1\end{array}$ \\
\hline
\end{tabular}


Table B.4. (Contd)

\begin{tabular}{rrrrrrrrrrr} 
Material & $\begin{array}{c}\text { Energy, } \\
\text { MeV }\end{array}$ & & $\underline{0.50}$ & $\underline{1.00}$ & $\underline{2.00}$ & $\underline{4.00}$ & $\underline{7.00}$ & $\underline{10.00}$ & $\underline{15.00}$ & $\underline{20.00}$ \\
\cline { 2 - 9 } & 4.0 & -- & 1.45 & 1.94 & 3.03 & 4.91 & 7.11 & 11.2 & 16.0 \\
& 6.0 & -- & 1.34 & 1.72 & 2.58 & 4.14 & 6.02 & 9.89 & 14.7 \\
& 10.0 & -- & 1.20 & 1.42 & 1.95 & 2.99 & 4.35 & 7.54 & 12.4 \\
Lead [8] & 0.5 & -- & 1.24 & 1.42 & 1.69 & 2.00 & 2.27 & 2.67 & 2.73 \\
& 1.0 & -- & 1.37 & 1.69 & 2.26 & 3.02 & 3.74 & 4.81 & 5.86 \\
& 2.0 & -- & 1.39 & 1.76 & 2.51 & 3.66 & 4.84 & 6.87 & 9.00 \\
& 3.0 & -- & 1.34 & 1.68 & 2.43 & 3.75 & 5.30 & 8.44 & 12.3 \\
& 4.0 & -- & 1.27 & 1.56 & 2.25 & 3.61 & 5.44 & 9.80 & 16.3 \\
& 6.0 & -- & 1.18 & 1.40 & 1.97 & 3.34 & 5.69 & 13.8 & 32.7 \\
& 10.0 & -- & 1.11 & 1.23 & 1.58 & 2.52 & 4.34 & 12.5 & 39.2
\end{tabular}

The photon energy flux to biological dose rate conversion factor is based on Table B.5.

Tables B.6 and B.4.5 present the results of the analyses of each source type. Table B.6 includes the average MeV values, photon intensities based on the material type, linear attenuation coefficients, and the energy to dose rate conversion factors. Table B.7 includes the buildup factors for concrete and steel based on the average MeV values. 
TABLE B.5. Photon Energy Flux to Biological
Dose Rate Conversion Factor

\begin{tabular}{|cl|}
\hline $\begin{array}{c}E \\
\mathrm{MeV}\end{array}$ & \multicolumn{1}{c|}{$\begin{array}{c}k_{\mathrm{m}}(\mathrm{E}) \\
\mathrm{rem} / \mathrm{hr} \mathrm{per} \mathrm{MeV} / \mathrm{cm}^{2} \mathrm{sec}\end{array}$} \\
\hline 0.5 & $2.33-06$ \\
0.6 & 2.26 \\
0.7 & 2.18 \\
0.8 & 2.10 \\
0.9 & 2.04 \\
1.0 & $1.98-05$ \\
1.2 & 1.89 \\
1.4 & 1.79 \\
1.6 & 1.72 \\
1.8 & 1.66 \\
2.0 & $1.60-06$ \\
2.2 & 1.55 \\
2.4 & 1.51 \\
2.6 & 1.47 \\
2.8 & 1.43 \\
3.0 & $1.40-06$ \\
3.2 & 1.37 \\
3.4 & 1.34 \\
3.6 & 1.32 \\
3.8 & 1.29 \\
4.0 & $1.26-06$ \\
4.2 & 1.24 \\
4.4 & 1.22 \\
4.6 & 1.20 \\
4.8 & 1.18 \\
5.0 & $1.16-06$ \\
\hline
\end{tabular}

\begin{tabular}{|cl|}
\hline & \multicolumn{1}{c|}{$\mathrm{k}_{\mathrm{m}}(\mathrm{E})$} \\
$\mathrm{MeV}$ & $\mathrm{rem} / \mathrm{hr} \mathrm{per} \mathrm{MeV} / \mathrm{cm}^{2} \mathrm{sec}$ \\
5.0 & $1.16-06$ \\
5.2 & 1.15 \\
5.4 & 1.13 \\
5.6 & 1.12 \\
5.8 & 1.10 \\
6.0 & $1.09-06$ \\
6.2 & 1.08 \\
6.4 & 1.07 \\
6.6 & 1.07 \\
6.8 & 1.06 \\
7.0 & $1.05-06$ \\
7.2 & 1.04 \\
7.4 & 1.03 \\
7.6 & 1.03 \\
7.8 & 1.02 \\
8.0 & $1.01-06$ \\
8.2 & 1.00 \\
8.4 & 0.99 \\
8.6 & 0.99 \\
8.8 & 0.98 \\
9.0 & $0.97-06$ \\
9.2 & 0.97 \\
9.4 & 0.96 \\
9.6 & 0.96 \\
9.8 & 0.95 \\
10.0 & $0.96-06$ \\
\hline
\end{tabular}

(a) Interpolated from data in: H. C. Claiborne and D. K. Trubey. 1970. "Dose Rates in a Slab Phantom from Monoenergetic Gamma Rays, " Nuc. Appl.Tech., $8: 450$. 
TABLE B.6. Summary of the Information Required to Determine the Radiological Dose Rates Based on the Material Type

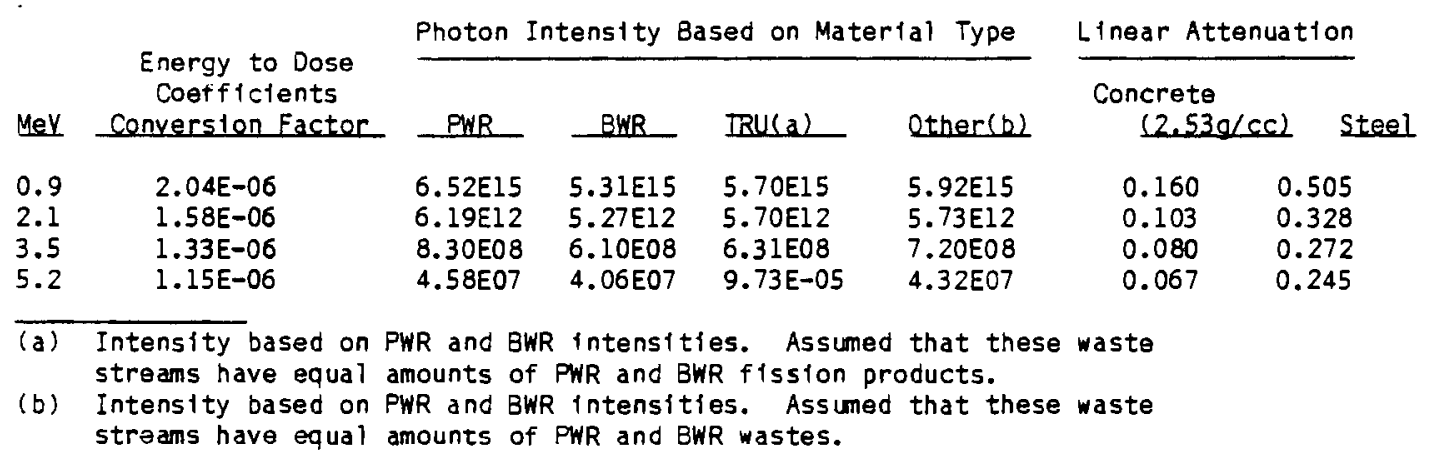

TABLE B.7. Gamma-Ray Exposure Buildup Factors Based on Material Type

$\begin{array}{lcllllllll}\text { Material } & \begin{array}{c}\text { Energy, } \\ \text { Mey }\end{array} & \mathbf{0 . 5 0} & 1.00 & 2.00 & 4.00 & \text { Z.00 } & 10.00 & 15.00 & 20.00 \\ \text { Concrete } & 0.9 & 1.47 & 2.04 & 3.41 & 6.96 & 14.3 & 24.0 & 45.1 & 72.1 \\ (2.53 \mathrm{~g} / \mathrm{cc}) & 2.1 & 1.37 & 1.77 & 2.64 & 4.57 & 7.86 & 11.5 & 18.2 & 25.5 \\ & 3.5 & 1.32 & 1.65 & 2.31 & 3.69 & 5.94 & 8.33 & 12.6 & 17.1 \\ & 5.2 & 1.28 & 1.53 & 2.03 & 3.03 & 4.59 & 6.20 & 8.97 & 11.8 \\ \text { Stee1 } & 0.9 & - & 1.89 & 2.93 & 5.67 & 10.5 & 16.8 & 29.7 & 45.3 \\ & 2.1 & - & 1.74 & 2.40 & 4.07 & 7.11 & 10.7 & 17.2 & 24.5 \\ & 3.5 & - & 1.50 & 2.05 & 3.27 & 5.38 & 7.81 & 12.4 & 17.6 \\ & 5.2 & - & 1.38 & 1.81 & 2.76 & 4.45 & 6.46 & 10.4 & 15.2\end{array}$




\section{APPENDIX B REFERENCES}

Croff, A. G., M. A. Bjerke, G. W. Morrison, and L. M. Petrie. 1978. Revised Uranium-Plutonium Cycle PWR and BWR Models for the Origen Computer Code, ORNL/TM-6051, Oak Ridge National Laboratory, Oak Ridge, Tennessee. 
APPENDIX C

DOSE CALCULATIONS 


\section{APPENDIX C}

\section{DOSE CALCULATIONS}

A simplifying assumption in EXCOMP was used when performing dose calculations. That is, a point source geometry is used for all types of materials in the facility. A point source was used to reduce any confusion that may exist when initially identifying source geometries in a facility. Also, in radioactive material processing facilities, it is difficult to predict the source geometry at each process location or in each waste stream. This also reduces the time required to perform an analysis. The calculated exposure rates are conservative, i.e., higher than expected, for distances less than two times the length of the source. However, as this distance increases, the source will tend to act as a point source.

The background information required to perform the necessary calculations are described in Appendices $A$ and $B$. This information includes the distance the source is from the work location, the thickness and type of each barrier encountered, the energy levels (MeV) and the quality of material present at each location. Table C.1 summarizes additional information necessary for the calculations (Appendix D presents the distance and barrier thickensses for the MRS).

The following discussion describes how the interpreter in ExCOMP uses the information in the facility and the source databases to calculate dose.

\section{C.1 CALCULATIONAL PROCEDURE}

EXCOMP locates the record of interest in the facility database, based on the target location (see Figure C.1). For information on the database structure see section 6 . The information describing the target location is read and then EXCOMP searches the source database for the source location identified in the target location description.

The information describing the source is read. EXCOMP then uses information read from the facility database describing the target location, information from the source database describing the source at a particular

$$
\text { C. } 1
$$


source location, and information internal to EXCOMP to calculate an estimated exposure rate.

Process

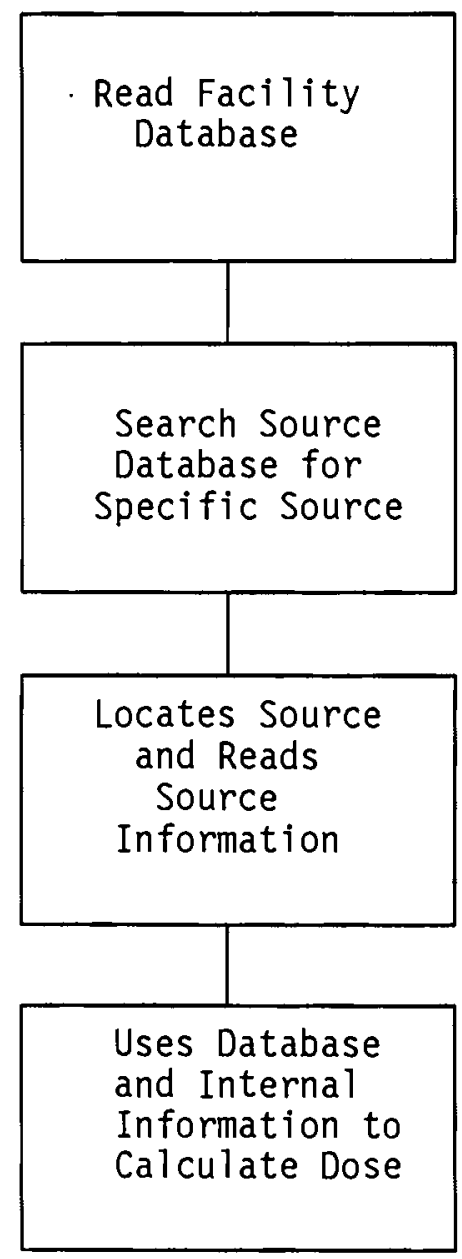

Description

Reads the target description: source location, distance from source, and barrier thickness.
Searches the source database for the source identified in the facility database.
Reads the source description: MeV, type of source, and quantity of material at that location.

Uses database information: distance, barrier, MeV, and quantity. Uses internal information: intensity, linear attenuation coefficients, flux to dose conversion factors and bases for buildup factors.

Calculates dose mrem/hr for the source location using this information.

FIGURE C.1. Simplified Flow Chart of EXCOMP Dose Calculational Procedure 


\section{C.2 DOSE CALCULATIONS}

EXCOMP estimates the exposure rate at a particular target location using a photon grouping method and equation 1 and 3 (Glasstone and Sesonske, 1981).

Equation 1 is repeated once for each photon grouping with the total exposure rate being the sum of the exposure rates for the four groupings. The total calculated exposure rate is in rem/hr per MTIHM. Equation 3 converts the exposure rate to $\mathrm{mrem} / \mathrm{hr}$ based on the quantity of material found at the source location.

(1) $r e m / h r=B F\left(I I e^{-\mu x} * M U\right) K E /\left(4 * \pi * D i s t^{2}\right)$

where:

BF is a buildup factor (interpolated from Table B.4.5), (a)

II is the initial source intensity (assigned from Table B.4.4), (b)

$\mu \mathrm{x}$ is a unitless factor relating barrier thickness to attenuation, (a)

MU is the average MeV value, (c)

KE is a factor converting energy flux to biological dose equivalent (assigned from Table B.4.4, (a) and

Dist is the distance from target to source in centimeters. (c)

(2) $\mu x=L A C *$ thickness

where:

LAC is a linear attenuation coefficient (assigned from Table B.4.4) (a) and, Thickness is the barrier thickness in centimeters. (c) 
(3) $\mathrm{mrem} / \mathrm{hr}=(\Sigma \mathrm{rem} / \mathrm{hr}) * 1000 \mathrm{mrem} / \mathrm{rem} * \mathrm{wt} \mathrm{kg} / \mathrm{MTIHM}$ 1

where:

n

$\Sigma$ sum of the calculated doses for each energy grouping ${ }^{(a)}$ and 1

wt is the quantity of material at a particular source location (c)
(a) Calculated from values internal to EXCOMP.
(b) Value is internal to EXCOMP.
(c) Value is read in from the database. 
TABLE C.1. Summary of Information Required for Dose Calculations

\begin{tabular}{|c|c|c|c|}
\hline$\frac{\text { Material }}{\text { PWR }}$ & $\begin{array}{l}\begin{array}{c}\text { Average } \\
\text { Mev }\end{array} \\
0.9 \\
2.1 \\
3.5 \\
5.2\end{array}$ & $\begin{array}{c}\begin{array}{c}\text { Photon } \\
\text { Release Rate }\end{array} \\
6.52 \mathrm{E} 15 \\
6.19 \mathrm{E} 12 \\
8.30 \mathrm{E} 08 \\
4.58 \mathrm{E} 07\end{array}$ & $\begin{array}{c}\text { Quantity of } \\
\text { Material (MTIHM) } \\
1.28\end{array}$ \\
\hline BWR & $\begin{array}{l}0.9 \\
2.1 \\
3.5 \\
5.2\end{array}$ & $\begin{array}{l}5.31 \mathrm{E} 15 \\
5.27 \mathrm{E} 12 \\
6.10 \mathrm{E} 08 \\
4.06 \mathrm{E} 07\end{array}$ & 1.38 \\
\hline LWR & $\begin{array}{l}0.9 \\
2.1 \\
3.5 \\
5.2\end{array}$ & $\begin{array}{l}5.92 \mathrm{E} 15(\mathrm{a}) \\
5.73 \mathrm{E} 12 \\
7.20 \mathrm{E} 08 \\
4.32 \mathrm{E} 07\end{array}$ & $1.5 \mathrm{E}-02$ \\
\hline HLW & $\begin{array}{l}0.9 \\
2.1 \\
3.5 \\
5.2\end{array}$ & $\begin{array}{l}5.92 \mathrm{E} 15(\mathrm{a}) \\
5.73 \mathrm{E} 12 \\
7.20 \mathrm{E} 08 \\
4.32 \mathrm{E} 07\end{array}$ & 1.00 \\
\hline SRW & $\begin{array}{l}0.9 \\
2.1 \\
3.5 \\
5.2\end{array}$ & $\begin{array}{l}5.92 \mathrm{E} 15(\mathrm{a}) \\
5.73 \mathrm{E} 12 \\
7.20 \mathrm{E} 08 \\
4.32 \mathrm{E} 07\end{array}$ & $1.0 \mathrm{E}-02$ \\
\hline RHE & $\begin{array}{l}0.9 \\
2.1 \\
3.5 \\
5.2\end{array}$ & $\begin{array}{l}5.92 \mathrm{E} 15(\mathrm{a}) \\
5.73 \mathrm{E} 12 \\
7.20 \mathrm{E} 08 \\
4.32 \mathrm{E} 07\end{array}$ & $5.0 \mathrm{E}-03$ \\
\hline CHE & $\begin{array}{l}0.9 \\
2.1 \\
3.5 \\
5.2\end{array}$ & $\begin{array}{l}5.92 \mathrm{E} 15(\mathrm{a}) \\
5.73 \mathrm{E} 12 \\
7.20 \mathrm{E} 08 \\
4.32 \mathrm{E} 07\end{array}$ & $5.0 \mathrm{E}-05$ \\
\hline TRU & $\begin{array}{l}0.9 \\
2.1 \\
3.5 \\
5.2\end{array}$ & $\begin{array}{l}5.70 \mathrm{E} 15(\mathrm{~b}) \\
5.70 \mathrm{E} 12 \\
6.31 \mathrm{E} 08 \\
9.73 \mathrm{E}-05\end{array}$ & 1.0E-03 \\
\hline
\end{tabular}

(a) Intensity based on PWR and BWR intensities. Assumed that these waste streams have equal amounts of PWR and BWR wastes.

(b) Intensity based on PWR and BWR intensities. Assumed that these waste streams have equal amounts on PWR and BWR fission products. 


\section{APPENDIX C REFERENCES}

Glasstone, S. and Sesonske, A. 1967. Nuclear Reactor Engineering. D. Van Nostrand Company, Inc., Princeton, New Jersey. 
APPENDIX D

MRS TARGET LOCATIONS 
TABLE D.1. Database Used to Characterize the Integral MRS Facility

\begin{tabular}{|c|c|}
\hline $\begin{array}{c}\text { Work } \\
\text { Location } \\
\end{array}$ & $\begin{array}{c}\text { Source } \\
\text { Location }\end{array}$ \\
\hline 1004 & 1063 \\
\hline 1004 & 1065 \\
\hline 1004 & 1070 \\
\hline 1004 & 1071 \\
\hline 1004 & 1073 \\
\hline 1004 & 1079 \\
\hline 1004 & 1084 \\
\hline 1004 & 1085 \\
\hline 1004 & 1086 \\
\hline 1004 & 1090 \\
\hline 1004 & 1091 \\
\hline 1004 & 1092 \\
\hline 1004 & 1113 \\
\hline 1004 & 1130 \\
\hline 1004 & 1135 \\
\hline 1004 & 1136 \\
\hline 1004 & 1141 \\
\hline 1004 & 1142 \\
\hline 1004 & 1162 \\
\hline 1004 & 1163 \\
\hline 1004 & 1164 \\
\hline 1004 & 1170 \\
\hline 1004 & 1171 \\
\hline 1004 & 1172 \\
\hline 1004 & 1179 \\
\hline 1020 & 1063 \\
\hline 1020 & 1064 \\
\hline 1020 & 1065 \\
\hline 1020 & 1070 \\
\hline 1020 & 1071 \\
\hline 1020 & 1073 \\
\hline 1020 & 1079 \\
\hline 1020 & 1084 \\
\hline 1020 & 1085 \\
\hline 1020 & 1086 \\
\hline 1020 & 1090 \\
\hline 1020 & 1091 \\
\hline 1020 & 1092 \\
\hline 1020 & 1113 \\
\hline 1020 & 1130 \\
\hline 1020 & 1135 \\
\hline 1020 & 1136 \\
\hline 1020 & 1141 \\
\hline 1020 & 1142 \\
\hline 1020 & 1162 \\
\hline 1020 & 1163 \\
\hline 1020 & 1164 \\
\hline 1020 & 1170 \\
\hline
\end{tabular}

Distance Thickness of Shielding Separating Work
from Work and Source Locations, (in feet).

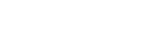

To Source

Location Existing Additional Additional Total

125

162

4.9
13.8
11.8
10.6
14.6
14.2
18.8
26.2
28.5
40.0
40.9
43.6
42.6
67.3
71.6
76.9
74.1
53.0
47.0
28.7
35.2
30.0
21.5
10.1
9.3
2.8
4.5
8.5
9.5
10.5
10.5
9.4
13.0
21.7
32.6
32.4
37.9
44.8
46.8
53.4
60.4
91.7
57.8
57.1
39.4
36.7
57.2
48.8
12.3
4

205

223

226

205

284

297

276

292

351

329

348

417

502

552

491

550

486

319

319

298

255

236

258

231

175

226

263

287

282

228

345

313

287

297

350

324

337

382

450

497

438

486

425

226

231

210

165

0.0

0.04 .9

0.0

$0.0 \quad 13.8$

0.0

0.011 .8

0.0

0.0

$0.0 \quad 10.6$

0.0

$0.0 \quad 14.6$

0.0

0.014 .2

0.0

0.018 .8

0.0

$0.0 \quad 26.2$

0.0

$0.0 \quad 28.5$

0.0

$0.0 \quad 40.0$

0.0

0.0

40.9

0.0

$0.0 \quad 43.6$

0.0

0.0

42.6

0.0

$0.0 \quad 67.3$

0.0

$0.0 \quad 71.6$

0.0

$0.0 \quad 76.9$

0.0

$0.0 \quad 74.1$

0.0

0.0

53.0

0.0

0.0

47.0

0.0

0 .

0.0

28.7

0.0

0.0

0.0

35.2

0.0

$0.0 \quad 21.5$

0.0

$0.0 \quad 10.1$

0.0

$0.0 \quad 9.3$

$0.0-2.8$

0.0

0.0

0.0

4.5

0.0

0.0

8.5

0.0

0.0

9.5

0.0

0 .

10.5

0.0

0.0

0.0

10.5

0.0

0.0

9.4

0.0

0 .

13.0

0.0

0 .

21.7

0.0

0 .

32.6

0.0

0.0

0.0

0.0

0.0

0.0

0.0

32.4

44.8

$0.0 \quad 46.8$

$0.0 \quad 53.4$

$0.0 \quad 60.4$

$0.0 \quad 91.7$

0.0

$0.0 \quad 57.8$

0.0

$0.0 \quad 57.1$

0.0

$0.0 \quad 39.4$

0.0

0.0

0.0

36.7

$0.0 \quad 57.2$

0.0

$0.0 \quad 48.8$

D. 1 
TABLE D.1. Continued

\begin{tabular}{|c|c|c|c|c|c|c|}
\hline \multirow{2}{*}{$\begin{array}{c}\text { Work } \\
\text { Location } \\
\end{array}$} & \multirow{2}{*}{$\begin{array}{c}\text { Source } \\
\text { Location }\end{array}$} & \multirow{2}{*}{$\begin{array}{l}\text { from Work } \\
\text { To Source } \\
\text { Location }\end{array}$} & \multicolumn{4}{|c|}{ and Source Locations, (in feet). } \\
\hline & & & Existing & Additional & Additional & Total \\
\hline 1020 & 1171 & 146 & 10.8 & 0.0 & 0.0 & 10.8 \\
\hline 1020 & 1172 & 162 & 5.5 & 0.0 & 0.0 & 5.5 \\
\hline 1020 & 1179 & 139 & 1.0 & 0.0 & 0.0 & 1.0 \\
\hline 1028 & 1063 & 148 & 4.5 & 0.0 & 0.0 & 4.5 \\
\hline 1028 & 1064 & 196 & 8.5 & 0.0 & 0.0 & 8.5 \\
\hline 1028 & 1065 & 234 & 9.5 & 0.0 & 0.0 & 9.5 \\
\hline 1028 & 1070 & 258 & 10.5 & 0.0 & 0.0 & 10.5 \\
\hline 1028 & 1071 & 252 & 10.6 & 0.0 & 0.0 & 10.6 \\
\hline 1028 & 1073 & 207 & 15.6 & 0.0 & 0.0 & 15.6 \\
\hline 1028 & 1079 & 319 & 13.0 & 0.0 & 0.0 & 13.0 \\
\hline 1028 & 1084 & 293 & 19.4 & 0.0 & 0.0 & 19.4 \\
\hline 1028 & 1085 & 268 & 23.3 & 0.0 & 0.0 & 23.3 \\
\hline 1028 & 1086 & 282 & 28.6 & 0.0 & 0.0 & 28.6 \\
\hline 1028 & 1090 & 338 & 40.9 & 0.0 & 0.0 & 40.9 \\
\hline 1028 & 1091 & 313 & 30.4 & 0.0 & 0.0 & 30.4 \\
\hline 1028 & 1092 & 327 & 33.7 & 0.0 & 0.0 & 33.7 \\
\hline 1028 & 1113 & 380 & 59.3 & 0.0 & 0.0 & 59.3 \\
\hline 1028 & 1130 & 462 & 56.1 & 0.0 & 0.0 & 56.1 \\
\hline 1028 & 1135 & 505 & 92.5 & 0.0 & 0.0 & 92.5 \\
\hline 1028 & 1136 & 444 & 71.9 & 0.0 & 0.0 & 71.9 \\
\hline 1028 & 1141 & 495 & 48.5 & 0.0 & 0.0 & 48.5 \\
\hline 1028 & 1142 & 433 & 42.0 & 0.0 & 0.0 & 42.0 \\
\hline 1028 & 1162 & 247 & 21.8 & 0.0 & 0.0 & 21.8 \\
\hline 1028 & 1163 & 250 & 33.3 & 0.0 & 0.0 & 33.3 \\
\hline 1028 & 1164 & 228 & 35.8 & 0.0 & 0.0 & 35.8 \\
\hline 1028 & 1170 & 184 & 14.8 & 0.0 & 0.0 & 14.8 \\
\hline 1028 & 1171 & 165 & 10.0 & 0.0 & 0.0 & 10.0 \\
\hline 1028 & 1172 & 186 & 9.1 & 0.0 & 0.0 & 9.1 \\
\hline 1028 & 1179 & 170 & 1.6 & 0.0 & 0.0 & 1.6 \\
\hline 1038 & 1063 & 151 & 4.6 & 0.0 & 0.0 & 4.6 \\
\hline 1038 & 1064 & 202 & 8.8 & 0.0 & 0.0 & 8.8 \\
\hline 1038 & 1065 & 236 & 9.6 & 0.0 & 0.0 & 9.6 \\
\hline 1038 & 1070 & 263 & 10.7 & 0.0 & 0.0 & 10.7 \\
\hline 1038 & 1071 & 250 & 10.5 & 0.0 & 0.0 & 10.5 \\
\hline 1038 & 1073 & 191 & 9.2 & 0.0 & 0.0 & 9.2 \\
\hline 1038 & 1079 & 319 & 13.1 & 0.0 & 0.0 & 13.1 \\
\hline 1038 & 1084 & 271 & 25.2 & 0.0 & 0.0 & 25.2 \\
\hline 1038 & 1085 & 244 & 33.4 & 0.0 & 0.0 & 33.4 \\
\hline 1038 & 1086 & 252 & 26.0 & 0.0 & 0.0 & 26.0 \\
\hline 1038 & 1090 & 308 & 58.6 & 0.0 & 0.0 & 58.6 \\
\hline 1038 & 1091 & 279 & 45.6 & 0.0 & 0.0 & 45.6 \\
\hline 1038 & 1092 & 292 & 44.2 & 0.0 & 0.0 & 44.2 \\
\hline 1038 & 1113 & 337 & 48.0 & 0.0 & 0.0 & 48.0 \\
\hline 1038 & 1130 & 414 & 67.7 & 0.0 & 0.0 & 67.7 \\
\hline 1038 & 1135 & 456 & 88.8 & 0.0 & 0.0 & 88.8 \\
\hline 1038 & 1136 & 396 & 80.8 & 0.0 & 0.0 & 80.8 \\
\hline 1038 & 1141 & 446 & 47.3 & 0.0 & 0.0 & 47.3 \\
\hline 1038 & 1142 & 385 & 41.3 & 0.0 & 0.0 & 41.3 \\
\hline 1038 & 1162 & 201 & 35.1 & 0.0 & 0.0 & 35.1 \\
\hline
\end{tabular}


TABLE D.1. Continued

\begin{tabular}{|c|c|}
\hline $\begin{array}{c}\text { Work } \\
\text { Location }\end{array}$ & $\begin{array}{r}\text { Source } \\
\text { Locatio } \\
\end{array}$ \\
\hline 1038 & 1163 \\
\hline 1038 & 1164 \\
\hline 1038 & 1170 \\
\hline 1038 & 1171 \\
\hline 1038 & 1172 \\
\hline 1038 & 1179 \\
\hline 1068 & 1063 \\
\hline 1068 & 1064 \\
\hline 1068 & 1065 \\
\hline 1068 & 1070 \\
\hline 1068 & 1071 \\
\hline 1068 & 1073 \\
\hline 1068 & 1079 \\
\hline 1068 & 1084 \\
\hline 1068 & 1085 \\
\hline 1068 & 1086 \\
\hline 1068 & 1090 \\
\hline 1068 & 1091 \\
\hline 1068 & 1092 \\
\hline 1068 & 1113 \\
\hline 1068 & 1130 \\
\hline 1068 & 1135 \\
\hline 1068 & 1136 \\
\hline 1068 & 1141 \\
\hline 1068 & 1142 \\
\hline 1068 & 1162 \\
\hline 1068 & 1163 \\
\hline 1068 & 1164 \\
\hline 1068 & 1170 \\
\hline 1068 & 1171 \\
\hline 1068 & 1172 \\
\hline 1068 & 1179 \\
\hline 10951 & 1063 \\
\hline 10951 & 1064 \\
\hline 10951 & 1065 \\
\hline 10951 & 1070 \\
\hline 10951 & 1071 \\
\hline 10951 & 1073 \\
\hline 10951 & 1079 \\
\hline 10951 & 1084 \\
\hline 10951 & 1085 \\
\hline 10951 & 1086 \\
\hline 10951 & 1090 \\
\hline 10951 & 1091 \\
\hline 10951 & 1092 \\
\hline 10951 & 1113 \\
\hline 10951 & 1130 \\
\hline 10951 & 1135 \\
\hline 10951 & 1136 \\
\hline
\end{tabular}

Distance Thickness of Shielding Separating Work
from Work and Source Locations, (in feet).

To Source
Location

202

181

138

122

146

162

122

72

40

19

53

130

61

170

175

191

239

239

258

364

457

531

470

550

494

433

417

404

367

359

401

433

151

162

161

178

138

74

199

69

40

42

93

71

88

175

268

337

276
36.4

29.0

27.2

10.7

10.1

1.5

10.3

6.2

2.9

1.1

2.1

10.0

4.9

9.0

18.7

26.3

11.5

29.0

24.4

60.1

64.0

91.8

71.2

70.3

64.6

67.7

61.7

60.3

47.6

46.7

68.8

30.8

5.6

4.5

13.5

13.1

10.2

1.5

12.5

12.6

7.2

7.2

18.8

16.3

16.2

8.0

17.0

75.6

65.2
0.0

0.0

0.0

0.0

0.0

0.0

0.0

0.0

0.0

0.0

0.0

0.0

0.0

0.0

0.0

0.0

0.0

0.0

0.0

0.0

0.0

0.0

0.0

0.0

0.0

0.0

0.0

0.0

0.0

0.0

0.0

0.0

0.0

0.0

0.0

0.0

0.0

0.0

0.0

0.0

0.0

0.0

0.0

0.0

0.0

0.0

0.0

0.0

0.0
0.0

0.0

0.027 .2

$0.0 \quad 10.7$

0.010 .1

0.01 .5

$0.0 \quad 10.3$

0.06 .2

$0.0 \quad 2.9$

0.01 .1

$0.0 \quad 2.1$

$0.0 \quad 10.0$

$0.0 \quad 4.9$

$0.0 \quad 9.0$

$\begin{array}{ll}0.0 & 18.7\end{array}$

0.026 .3

$0.0 \quad 11.5$

0.029 .0

$0.0 \quad 24.4$

0.060 .1

$0.0 \quad 64.0$

$0.0 \quad 91.8$

0.071 .2

0.070 .3

0.064 .6

$0.0 \quad 67.7$

0.061 .7

0.060 .3

$0.0 \quad 47.6$

$0.0 \quad 46.7$

0.068 .8

$0.0 \quad 30.8$

$0.0 \quad 5.6$

$0.0 \quad 4.5$

0.013 .5

0.013 .1

0.010 .2

0.01 .5

0.012 .5

0.012 .6

$0.0 \quad 7.2$

$0.0 \quad 7.2$

$0.0 \quad 18.8$

0.016 .3

0.016 .2

$0.0 \quad 8.0$

$0.0 \quad 17.0$

$0.0 \quad 75.6$

$0.0 \quad 65.2$

D. 3 
TABLE D.1. Continued

$\begin{gathered}\text { Source } \\ \text { Location }\end{gathered}$
Location

$\begin{array}{ll}10951 & 1141 \\ 10951 & 1142 \\ 10951 & 1162 \\ 10951 & 1163 \\ 10951 & 1164 \\ 10951 & 1170 \\ 10951 & 1171 \\ 10951 & 1172 \\ 10951 & 1179 \\ 10952 & 1063 \\ 10952 & 1064 \\ 10952 & 1065 \\ 10952 & 1070 \\ 10952 & 1071 \\ 10952 & 1073 \\ 10952 & 1079 \\ 10952 & 1084 \\ 10952 & 1085 \\ 10952 & 1086 \\ 10952 & 1090 \\ 10952 & 1091 \\ 10952 & 1092 \\ 10952 & 1113 \\ 10952 & 1130 \\ 10952 & 1135 \\ 10952 & 1136 \\ 10952 & 1141 \\ 10952 & 1142 \\ 10952 & 1162 \\ 10952 & 1163 \\ 10952 & 1164 \\ 10952 & 1170 \\ 10952 & 1171 \\ 10952 & 1172 \\ 10952 & 1179 \\ 11061 & 1063 \\ 11061 & 1064 \\ 11061 & 1065 \\ 11061 & 1070 \\ 11061 & 1071 \\ 11061 & 1073 \\ 11061 & 1079 \\ 11061 & 1084 \\ 11061 & 1085 \\ 11061 & 1086 \\ 11061 & 1090 \\ 11061 & 1091 \\ 11061 & 1092 \\ 11061 & 1113 \\ 106 & \\ & \end{array}$
Distance Thickness of Shielding Separating Work
from Work and Source Locations, (in feet). To Source Location Existing Additional Additional Total

353

295

279

258

252

246

247

276

361

154

162

226

241

204

141

254

69

85

69

72

42

42

106

201

271

210

291

236

271

244

244

250

255

284

388

226

250

255

274

240

163

298

157

133

122

133

104

99

112
63.4

60.4

53.6

32.4

35.4

32.0

27.5

33.0

34.8

25.6

4.5

25.0

24.6

35.7

1.5

36.2

25.8

26.1

11.9

12.5

7.3

7.2

8.0

17.0

93.4

44.2

59.4

39.0

42.0

16.0

36.6

15.7

21.7

15.5

42.9

32.4

18.4

22.9

28.5

22.9

14.8

31.9

24.7

22.2

18.1

12.6

7.1

7.0
0.0

0.0

0.0

0.0

0.0

0.0

0.0

0.0

0.0

0.0

0.0

0.0

0.0

0.0

0.0

0.0

0.0

0.0

0.0

0.0

0.0

0.0

0.0

0.0

0.0

0.0

0.0

0.0

0.0

0.0

0.0

0.0

0.0

0.0

0.0

0.0

0.0

0.0

0.0

0.0

0.0

0.0

0.0

0.0

0.0

0.0

0.0

0.0

0.0
0.0

$0.0 \quad 60.4$

$0.0 \quad 53.6$

$0.0 \quad 32.4$

$0.0 \quad 35.4$

0.032 .0

$0.0 \quad 27.5$

0.033 .0

0.034 .8

$0.0 \quad 25.6$

$0.0 \quad 4.5$

0.025 .0

$0.0 \quad 24.6$

$0.0 \quad 35.7$

$0.0 \quad 1.5$

0.036 .2

$0.0 \quad 25.8$

0.026 .1

0.011 .9

0.012 .5

$0.0 \quad 7.3$

0.07 .2

0.08 .0

$0.0 \quad 17.0$

$0.0 \quad 93.4$

0.0 .44 .2

$0.0 \quad 59.4$

$0.0 \quad 39.0$

0.042 .0

$0.0 \quad 16.0$

$0.0 \quad 36.6$

0.015 .7

$0.0 \quad 21.7$

$0.0 \quad 15.5$

$0.0 \quad 42.9$

$0.0 \quad 32.4$

$0.0 \quad 18.4$

0.022 .9

0.028 .5

$0.0 \quad 22.9$

0.014 .8

$0.0 \quad 31.9$

$0.0 \quad 24.7$

0.022 .2

0.018 .1

0.012 .6

$0.0 \quad 7.1$

$0.0 \quad 7.0$

$0.0 \quad 29.3$ 
TABLE D.1. Continued

\section{Work Source \\ Location Location}

$11061 \quad 1130$

$11061 \quad 1135$

$11061 \quad 1136$

$11061 \quad 1141$

$11061 \quad 1142$

$11061 \quad 1162$

$11061 \quad 1163$

$11061 \quad 1164$

$11061 \quad 1170$

$11061 \quad 1171$

$11061 \quad 1172$

$11061 \quad 1179$

$11062 \quad 1063$

$11062 \quad 1064$

$11062 \quad 1065$

$11062 \quad 1070$

$11062 \quad 1071$

$11062 \quad 1073$

$11062 \quad 1079$

$11062 \quad 1084$

$11062 \quad 1085$

$11062 \quad 1086$

$11062 \quad 1090$

$11062 \quad 1091$

$11062 \quad 1092$

$11062 \quad 1113$

$11062 \quad 1130$

$11062 \quad 1135$

$11062 \quad 1136$

$11062 \quad 1141$

$11062 \quad 1142$

$11062 \quad 1162$

$11062 \quad 1163$

$11062 \quad 1164$

$11062 \quad 1170$

$11062 \quad 1171$

$11062 \quad 1172$

$11062 \quad 1179$

$1115 \quad 1063$

$1115 \quad 1064$

$1115 \quad 1065$

$1115 \quad 1070$

$1115 \quad 1071$

$1115 \quad 1073$

$1115 \quad 1079$

$1115 \quad 1084$

$1115 \quad 1085$

$1115 \quad 1086$

$1115 \quad 1090$

Distance Thickness of Shielding Separating Work from Work and Source Locations, (in feet).

To Source

Location Existing Additional Additional Total

\section{7}

252

191

262

202

212

183

185

197

205

228

343

250

286

300

324

292

212

361

231

202

196

215

186

183

169

228

263

199

255

191

130

100

101

120

132

151

274

271

282

276

290

255

194

297

146

133

114

88
23.6

30.0

24.1

64.2

36.8

12.5

7.0

16.6

28.8

21.4

34.7

38.8

28.7

36.1

39.8

45.0

46.8

38.0

36.6

38.4

21.2

27.2

12.5

16.6

7.0

34.7

47.6

61.8

36.8

28.5

24.0

12.5

7.0

16.8

23.2

30.2

20.6

35.3

44.1

$$
4.5
$$

47.5

47.2

42.6

1.5

40.0

29.5

31.2

27.3

15.8
0.0

0.0

0.0

0.0

0.0

0.0

0.0

0.0

0.0

0.0

0.0

0.0

0.0

0.0

0.0

0.0

0.0

0.0

0.0

0.0

0.0

0.0

0.0

0.0

0.0

0.0

0.0

0.0

0.0

0.0

0.0

0.0

0.0

0.0

0.0

0.0

0.0

0.0

0.0

0.0

0.0

0.0

0.0

0.0

0.0

0.0

0.0

0.0

0.0
0.0

0.0

0.0

$0.0 \quad 64.2$

0.036 .8

$0.0 \quad 12.5$

$0.0 \quad 7.0$

$0.0 \quad 16.6$

$0.0 \quad 28.8$

$0.0 \quad 21.4$

$0.0 \quad 34.7$

$0.0 \quad 38.8$

$0.0 \quad 28.7$

0.036 .1

$0.0 \quad 39.8$

$0.0 \quad 45.0$

$0.0 \quad 46.8$

$0.0 \quad 38.0$

0.036 .6

0.038 .4

$0.0 \quad 21.2$

$0.0 \quad 27.2$

$0.0 \quad 12.5$

$0.0 \quad 16.6$

$0.0 \quad 7.0$

0.0 .34 .7

$0.0 \quad 47.6$

$0.0 \quad 61.8$

$0.0 \quad 36.8$

$0.0 \quad 28.5$

$0.0 \quad 24.0$

$0.0 \quad 12.5$

$0.0 \quad 7.0$

$0.0 \quad 16.8$

$0.0 \quad 23.2$

0.030 .2

$0.0 \quad 20.6$

0.035 .3

0.044 .1

0.04 .5

$0.0 \quad 47.5$

$0.0 \quad 47.2$

$0.0 \quad 42.6$

$0.0 \quad 1.5$

$0.0 \quad 40.0$

$0.0 \quad 29.5$

0.031 .2

$0.0 \quad 27.3$

$0.0 \quad 15.8$ 
TABLE D.1. Continued

\begin{tabular}{|c|c|c|c|c|c|c|}
\hline & & To & & & & \\
\hline Location & Location & Location & Existing & Additional & Additional & Total \\
\hline 1115 & 1091 & 72 & 21.6 & 0.0 & 0.0 & 21.6 \\
\hline 1115 & 1092 & 56 & 7.5 & 0.0 & 0.0 & 7.5 \\
\hline 1115 & 1113 & 56 & 8.0 & 0.0 & 0.0 & 8.0 \\
\hline 1115 & 1130 & 149 & 17.1 & 0.0 & 0.0 & 17.1 \\
\hline 1115 & 1135 & 223 & 54.8 & 0.0 & 0.0 & 54.8 \\
\hline 1115 & 1136 & 165 & 54.8 & 0.0 & 0.0 & 54.8 \\
\hline 1115 & 1141 & 239 & 46.8 & 0.0 & 0.0 & 46.8 \\
\hline 1115 & 1142 & 199 & 37.9 & 0.0 & 0.0 & 37.9 \\
\hline 1115 & 1162 & 282 & 68.8 & 0.0 & 0.0 & 68.8 \\
\hline 1115 & 1163 & 252 & 72.8 & 0.0 & 0.0 & 72.8 \\
\hline 1115 & 1164 & 258 & 47.0 & 0.0 & 0.0 & 47.0 \\
\hline 1115 & 1170 & 271 & 52.6 & 0.0 & 0.0 & 52.6 \\
\hline 1115 & 1171 & 279 & 46.7 & 0.0 & 0.0 & 46.7 \\
\hline 1115 & 1172 & 305 & 60.7 & 0.0 & 0.0 & 60.7 \\
\hline 1115 & 1179 & 417 & 52.7 & 0.0 & 0.0 & 52.7 \\
\hline 1159 & 1063 & 327 & 47.6 & 0.0 & 0.0 & 47.6 \\
\hline 1159 & 1064 & 369 & 38.3 & 0.0 & 0.0 & 38.3 \\
\hline 1159 & 1065 & 388 & 48.3 & 0.0 & 0.0 & 48.3 \\
\hline 1159 & 1070 & 412 & 49.2 & 0.0 & 0.0 & 49.2 \\
\hline 1159 & 1071 & 382 & 49.5 & 0.0 & 0.0 & 49.5 \\
\hline 1159 & 1073 & 300 & 40.9 & 0.0 & 0.0 & 40.9 \\
\hline 1159 & 1079 & 449 & 57.0 & 0.0 & 0.0 & 57.0 \\
\hline 1159 & 1084 & 324 & 64.3 & 0.0 & 0.0 & 64.3 \\
\hline 1159 & 1085 & 295 & 39.5 & 0.0 & 0.0 & 39.5 \\
\hline 1159 & 1086 & 290 & 55.0 & 0.0 & 0.0 & 55.0 \\
\hline 1159 & 1091 & 274 & 56.8 & 0.0 & $0.0^{\circ}$ & 56.8 \\
\hline 1159 & 1092 & 271 & 61.7 & 0.0 & 0.0 & 61.7 \\
\hline 1159 & 1113 & 228 & 31.2 & 0.0 & 0.0 & 31.2 \\
\hline 1159 & 1130 & 261 & 53.3 & 0.0 & 0.0 & 53.3 \\
\hline 1159 & 1135 & 266 & 44.1 & 0.0 & 0.0 & 44.1 \\
\hline 1159 & 1136 & 218 & 31.8 & 0.0 & 0.0 & 31.8 \\
\hline 1159 & 1141 & 236 & 48.7 & 0.0 & 0.0 & 48.7 \\
\hline 1159 & 1142 & 181 & 33.3 & 0.0 & 0.0 & 33.3 \\
\hline 1159 & 1162 & 64 & 17.0 & 0.0 & 0.0 & 17.0 \\
\hline 1159 & 1163 & 40 & 7.1 & 0.0 & 0.0 & 7.1 \\
\hline 1159 & 1164 & 58 & 10.7 & 0.0 & 0.0 & 10.7 \\
\hline 1159 & 1170 & 106 & 21.8 & 0.0 & 0.0 & 21.8 \\
\hline 1159 & 1171 & 125 & 25.7 & 0.0 & 0.0 & 25.7 \\
\hline 1159 & 1172 & 125 & 27.6 & 0.0 & 0.0 & 27.6 \\
\hline 1159 & 1179 & 255 & 34.5 & 0.0 & 0.0 & 34.5 \\
\hline 1159 & 1090 & 303 & 54.0 & 0.0 & 0.0 & 54.0 \\
\hline 11661 & 1063 & 231 & 20.1 & 0.0 & 0.0 & 20.1 \\
\hline 11661 & 1064 & 276 & 31.8 & 0.0 & 0.0 & 31.8 \\
\hline 11661 & 1065 & 303 & 33.5 & 0.0 & 0.0 & 33.5 \\
\hline 11661 & 1070 & 329 & 37.3 & 0.0 & 0.0 & 37.3 \\
\hline 11661 & 1071 & 305 & 39.4 & 0.0 & 0.0 & 39.4 \\
\hline 11661 & 1073 & 228 & 33.6 & 0.0 & 0.0 & 33.6 \\
\hline 11661 & 1079 & 377 & 40.5 & 0.0 & 0.0 & 40.5 \\
\hline 11661 & 1084 & 279 & 33.5 & 0.0 & 0.0 & 33.5 \\
\hline & & & D.t & & & \\
\hline
\end{tabular}


TABLE D.1. Continued

\begin{tabular}{|c|c|c|c|c|c|c|}
\hline \multirow{2}{*}{$\begin{array}{c}\text { Work } \\
\text { Location } \\
\end{array}$} & \multirow{2}{*}{$\begin{array}{l}\text { Source } \\
\text { Location }\end{array}$} & \multirow{2}{*}{$\begin{array}{l}\text { Trom work } \\
\text { To Source } \\
\text { Location }\end{array}$} & \multicolumn{4}{|c|}{ and source Locations, } \\
\hline & & & Existing & Additional & Additional & Total \\
\hline 11661 & 1085 & 249 & 28.0 & 0.0 & 0.0 & 28.0 \\
\hline 11661 & 1086 & 249 & 48.6 & 0.0 & 0.0 & 48.6 \\
\hline 11661 & 1090 & 286 & 21.0 & 0.0 & 0.0 & 21.0 \\
\hline 11661 & 1091 & 255 & 15.4 & 0.0 & 0.0 & 15.4 \\
\hline 11661 & 1092 & 260 & 15.8 & 0.0 & 0.0 & 15.8 \\
\hline 11661 & 1113 & 265 & 42.7 & 0.0 & 0.0 & 42.7 \\
\hline 11661 & 1130 & 327 & 61.4 & 0.0 & 0.0 & 61.4 \\
\hline 11661 & 1135 & 355 & 50.5 & 0.0 & 0.0 & 50.5 \\
\hline 11661 & 1136 & 297 & 50.6 & 0.0 & 0.0 & 50.6 \\
\hline 11661 & 1141 & 337 & 74.6 & 0.0 & 0.0 & 74.6 \\
\hline 11661 & 1142 & 276 & 60.5 & 0.0 & 0.0 & 60.5 \\
\hline 11661 & 1162 & 93 & 20.5 & 0.0 & 0.0 & 20.5 \\
\hline 11661 & 1163 & 85 & 21.0 & 0.0 & 0.0 & 21.0 \\
\hline 11661 & 1164 & 66 & 19.7 & 0.0 & 0.0 & 19.7 \\
\hline 11661 & 1170 & 37 & 7.3 & 0.0 & 0.0 & 7.3 \\
\hline 11661 & 1171 & 37 & 7.2 & 0.0 & 0.0 & 7.2 \\
\hline 11661 & 1172 & 66 & 0.0 & 0.0 & 0.0 & 0.0 \\
\hline 11661 & 1179 & 175 & 16.9 & 0.0 & 0.0 & 16.9 \\
\hline 11662 & 1063 & 277 & 31.8 & 0.0 & 0.0 & 31.8 \\
\hline 11662 & 1064 & 319 & 56.4 & 0.0 & 0.0 & 56.4 \\
\hline 11662 & 1065 & 340 & 36.3 & 0.0 & 0.0 & 36.3 \\
\hline 11662 & 1070 & 367 & 39.9 & 0.0 & 0.0 & 39.9 \\
\hline 11662 & 1071 & 337 & 39.5 & 0.0 & 0.0 & 39.5 \\
\hline 11662 & 1073 & 255 & 25.4 & 0.0 & 0.0 & 25.4 \\
\hline 11662 & 1079 & 404 & 36.1 & 0.0 & 0.0 & 36.1 \\
\hline 11662 & 1084 & 287 & 21.3 & 0.0 & 0.0 & 21.3 \\
\hline 11662 & 1085 & 258 & 32.9 & 0.0 & 0.0 & 32.9 \\
\hline 11662 & 1086 & 255 & 15.4 & 0.0 & 0.0 & 15.4 \\
\hline 11662 & 1090 & 279 & 20.5 & 0.0 & 0.0 & 20.5 \\
\hline 11662 & 1091 & 247 & 15.0 & 0.0 & 0.0 & 15.0 \\
\hline 11662 & 1092 & 247 & 27.5 & 0.0 & 0.0 & 27.5 \\
\hline 11662 & 1113 & 228 & 38.9 & 0.0 & 0.0 & 38.9 \\
\hline 11662 & 1130 & 276 & 55.3 & 0.0 & 0.0 & 55.3 \\
\hline 11662 & 1135 & 295 & 56.2 & 0.0 & 0.0 & 56.2 \\
\hline 11662 & 1136 & 242 & 35.5 & 0.0 & 0.0 & 35.5 \\
\hline 11662 & 1141 & 274 & 59.2 & 0.0 & 0.0 & 59.2 \\
\hline 11662 & 1142 & 213 & 52.5 & 0.0 & 0.0 & 52.5 \\
\hline 11662 & 1162 & 66 & 12.5 & 0.0 & 0.0 & 12.5 \\
\hline 11662 & 1163 & 37 & 7.3 & 0.0 & 0.0 & 7.3 \\
\hline 116 & 1164 & 37 & 7.2 & 0.0 & 0.0 & 7.2 \\
\hline 11662 & 1170 & 66 & 12.5 & 0.0 & 0.0 & 12.5 \\
\hline 11662 & 1171 & 85 & 19.9 & 0.0 & 0.0 & 19.9 \\
\hline 11662 & 1172 & 96 & 19.8 & 0.0 & 0.0 & 19.8 \\
\hline 11662 & 1179 & 226 & 32.1 & 0.0 & 0.0 & 32.1 \\
\hline 2004 & 2015 & 98 & 12.4 & 0.0 & 0.0 & 12.4 \\
\hline 2004 & 2017 & 155 & 36.0 & 0.0 & 0.0 & 36.0 \\
\hline 2004 & 2023 & 109 & 18.9 & 0.0 & 0.0 & 18.9 \\
\hline 2004 & 2024 & 74 & 9.6 & 0.0 & 0.0 & 9.6 \\
\hline 2004 & 2050 & 184 & 25.5 & 0.0 & 0.0 & 25.5 \\
\hline
\end{tabular}


TABLE D.1. Continued

\section{Work Source}

$2004 \quad 2052$

$2006 \quad 2015$

$.2006 \quad 2017$

$2006 \quad 2023$

$2006 \quad 2024$

$2006 \quad 2050$

$2006 \quad 2052$

$20111 \quad 2015$

$20111 \quad 2017$

201112023

$20111 \quad 2024$

201112050

201112052

$20181 \quad 2015$

$20181 \quad 2017$

$20181 \quad 2023$

$20181 \quad 2024$

$20181 \quad 2050$

$20181 \quad 2052$

$2019 \quad 2015$

$2019 \quad 2017$

$2019 \quad 2023$

$2019 \quad 2024$

$2019 \quad 2050$

$2019 \quad 2052$

$2022 \quad 2015$

$2022 \quad 2017$

$2022 \quad 2023$

$2022 \quad 2024$

$2022 \quad 2050$

$2022 \quad 2052$

$20251 \quad 2015$

$20251 \quad 2017$

$20251 \quad 2023$

$20251 \quad 2024$

$20251 \quad 2050$

$20251 \quad 2052$

$2027 \quad 2015$

$2027 \quad 2017$

$2027 \quad 2023$

$2027 \quad 2024$

$2027 \quad 2050$

$2027 \quad 2052$

203412015

$20341 \quad 2015$

203412023

203412024

203412050

203412052
Distance Thickness of Shielding Separating Work from Work and Source Locations, (in feet).

To Source

Location Existing Additional Additional Total

154

93

24.5

0.0

0.0

0.0

0.0

125

72

212

175

56

78

202

114

268

260

24

93

148

63

224

204

80

101

67

24

146

125

123

146

24

66

98

80

160

95

117

27

200

239

93

27

173

109

205

223

285

215

88

27

258

316
28.1

20.8

11.2

36.1

28.8

5.5

23.7

16.5

11.0

26.9

26.0

5.5

16.5

50.3

19.1

31.1

64.8

7.6

12.2

13.2

2.2

19.2

18.0

18.1

19.5

2.2

13.2

11.8

7.0

19.8

8.4

16.5

5.5

24.9

30.1

16.5

5.5

18.1

10.0

22.3

37.3

48.4

34.4

31.4

5.5

34.7

42.5
0.0

0.0

0.0

0.0

0.0

0.0

0.0

0.0

0.0

0.0

0.0

0.0

0.0

0.0

0.0

0.0

0.0

0.0

0.0

0.0

0.0

0.0

0.0

0.0

0.0

0.0

0.0

0.0

0.0

0.0

0.0

0.0

0.0

0.0

0.0

0.0

0.0

0.0

0.0

0.0

0.0

0.0

0.0

0.0

0.0
$0.0 \quad 24.5$

$0.0 \quad 14.1$

0.028 .1

$0.0 \quad 20.8$

$0.0 \quad 11.2$

$0.0 \quad 36.1$

$0.0 \quad 28.8$

$0.0 \quad 5.5$

$0.0 \quad 23.7$

$0.0 \quad 16.5$

$0.0 \quad 11.0$

$0.0 \quad 26.9$

0.026 .0

$0.0 \quad 5.5$

$0.0 \quad 16.5$

$0.0 \quad 50.3$

$0.0 \quad 19.1$

$0.0 \quad 31.1$

$0.0 \quad 64.8$

$0.0 \quad 7.6$

$0.0 \quad 12.2$

$0.0 \quad 13.2$

$0.0 \quad 2.2$

$0.0 \quad 19.2$

$0.0 \quad 18.0$

0.0 .18 .1

0.019 .5

$0.0 \quad 2.2$

$0.0 \quad 13.2$

0.011 .8

0.07 .0

0.019 .8

0.08 .4

$0.0 \quad 16.5$

$0.0 \quad 5.5$

$0.0 \quad 24.9$

0.030 .1

0.016 .5

$0.0 \quad 5.5$

$0.0 \quad 18.1$

$0.0 \quad 10.0$

$0.0 \quad 22.3$

$0.0 \quad 37.3$

$0.0 \quad 48.4$

$0.0 \quad 34.4$

$0.0 \quad 31.4$

$0.0 \quad 5.5$

$0.0 \quad 34.7$

$0.0 \quad 42.5$

D. 8 
TABLE D.1. Continued

Distance Thickness of Shielding Separating Work

$\begin{array}{cc}\text { Work } & \text { Source } \\ \text { Location } & \text { Location }\end{array}$

\section{$20401 \quad 2015$}

$20401 \quad 2017$

$20401 \quad 2023$

$20401 \quad 2024$

$20401 \quad 2050$

$20401 \quad 2052$

$2041 \quad 2015$

$2041 \quad 2017$

$2041 \quad 2023$

$2041 \quad 2024$

$2041 \quad 2050$

$2041 \quad 2052$

$2045 \quad 2015$

$2045 \quad 2017$

$2045 \quad 2023$

$2045 \quad 2024$

$2045 \quad 2050$

$2045 \quad 2052$

$20461 \quad 2015$

$20461 \quad 2017$

$20461 \quad 2023$

$20461 \quad 2024$

$20461 \quad 2050$

$20461 \quad 2052$

$20112 \quad 2015$

$20112 \quad 2017$

$20112 \quad 2023$

$20112 \quad 2024$

$20112 \quad 2050$

$20112 \quad 2052$

$20182 \quad 2015$

$20182 \quad 2017$

$20182 \quad 2023$

$20182 \quad 2024$

$20182 \quad 2050$

$20182 \quad 2052$

$20183 \quad 2015$

$20183 \quad 2017$

$20183 \quad 2023$

$20183 \quad 2024$

$20183 \quad 2050$

$20183 \quad 2052$

$20184 \quad 2015$

$20184 \quad 2017$

$20184 \quad 2023$

$20184 \quad 2024$

$20184 \quad 2050$

$20184 \quad 2052$

$20252 \quad 2015$ from Work and Source Locations, (in feet).

To Source

Location Existing Additional Additional Total

\begin{tabular}{|c|c|c|c|c|}
\hline 234 & 29.2 & 0.0 & 0.0 & 29.2 \\
\hline 197 & 24.5 & 0.0 & 0.0 & 24.5 \\
\hline 32 & 5.5 & 0.0 & 0.0 & 5.5 \\
\hline 117 & 16.5 & 0.0 & 0.0 & 16.5 \\
\hline 90 & 5.9 & 0.0 & 0.0 & 5.9 \\
\hline 155 & 16.8 & 0.0 & 0.0 & 16.8 \\
\hline 244 & 30.7 & 0.0 & 0.0 & 30.7 \\
\hline 205 & 23.5 & 0.0 & 0.0 & 23.5 \\
\hline 43 & 2.3 & 0.0 & 0.0 & 2.3 \\
\hline 109 & 13.8 & 0.0 & 0.0 & 13.8 \\
\hline 133 & 25.2 & 0.0 & 0.0 & 25.2 \\
\hline 199 & 43.3 & 0.0 & 0.0 & 43.3 \\
\hline 226 & 33.3 & 0.0 & 0.0 & 33.3 \\
\hline 207 & 22.2 & 0.0 & 0.0 & 22.2 \\
\hline 85 & 7.6 & 0.0 & 0.0 & 7.6 \\
\hline 157 & 17.9 & 0.0 & 0.0 & 17.9 \\
\hline 29 & 5.5 & 0.0 & 0.0 & 5.5 \\
\hline 96 & 16.5 & 0.0 & 0.0 & 16.5 \\
\hline 260 & 26.0 & 0.0 & 0.0 & 26.0 \\
\hline 268 & 26.8 & 0.0 & 0.0 & 26.8 \\
\hline 58 & 11.0 & 0.0 & 0.0 & 11.0 \\
\hline 146 & 22.0 & 0.0 & 0.0 & 22.0 \\
\hline 85 & 23.5 & 0.0 & 0.0 & 23.5 \\
\hline 56 & 5.5 & 0.0 & 0.0 & 5.5 \\
\hline 77 & 23.5 & 0.0 & 0.0 & 23.5 \\
\hline 56 & 5.5 & 0.0 & $0.0^{\circ}$ & .5 \\
\hline 218 & 38.0 & 0.0 & 0.0 & 38.0 \\
\hline 146 & 29.2 & 0.0 & 0.0 & 29.2 \\
\hline 260 & 26.0 & 0.0 & 0.0 & 26.0 \\
\hline 268 & 34.1 & 0.0 & 0.0 & 34.1 \\
\hline 64 & 19.5 & 0.0 & 0.0 & 19.5 \\
\hline 104 & 19.5 & 0.0 & 0.0 & 19.5 \\
\hline 90 & 19.5 & 0.0 & 0.0 & 19.5 \\
\hline 26 & 5.5 & 0.0 & 0.0 & 5.5 \\
\hline 173 & 24.1 & 0.0 & 0.0 & 24.1 \\
\hline 146 & 38.8 & 0.0 & 0.0 & 38.8 \\
\hline 148 & 38.8 & 0.0 & 0.0 & 38.8 \\
\hline 172 & 32.2 & 0.0 & 0.0 & 32.2 \\
\hline 24 & 5.5 & 0.0 & 0.0 & 5.5 \\
\hline 91 & 33.5 & 0.0 & 0.0 & 33.5 \\
\hline 98 & 20.6 & 0.0 & 0.0 & 20.6 \\
\hline 62 & 19.5 & 0.0 & 0.0 & 19.5 \\
\hline 205 & 64.8 & 0.0 & 0.0 & 64.8 \\
\hline 223 & 38.2 & 0.0 & 0.0 & 38.2 \\
\hline 64 & 19.1 & 0.0 & 0.0 & 19. \\
\hline 148 & 46.9 & 0.0 & 0.0 & 46.9 \\
\hline 93 & 16.5 & 0.0 & 0.0 & 16.5 \\
\hline 24 & 5.5 & 0.0 & 0.0 & 3 \\
\hline 255 & 19.6 & 0.0 & 0.0 & 19 \\
\hline
\end{tabular}




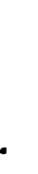




\section{DISTRIBUTION}

No. of

Copies

OFFSITE

B. C. Rusche

Office of Civilian Radioactive Waste Management

U.S. Department of Energy

$\mathrm{RW}-1$

Washington, D.C. 20545

J. R. Hilley

Office of Civilian Radioactive Waste Management

U.S. Department of Energy

$\mathrm{RW}-30$

Washington, D.C. 90545

K. A. Klein

Office of Civilian Radioactive Waste Management

U.S. Department of Energy

J. H. Carlson

Office of Civilian Radioactive Waste Management

U.S. Department of Energy

$\mathrm{RW}-32$

Washington, D.C. 90545

L. H. Barrett

Office of Civilian Radioactive Waste Management

U.S. Department of Energy

$\mathrm{RW}-31$

Washington, D.C. 90545

R. E. Philpott

Office of Civilian Radioactive

Waste Management

U.S. Department of Energy

$\mathrm{RW}-33$

Washington, D.C. 90545
No. of

Copies

E. L. Wilmot

Office of Civilian Radioactive Waste Management

U.S. Department of Energy

RW-33

Washington, D.C. 90545

R. Stein

Office of Civilian Radioactive Waste Management

U.S. Department of Energy

RW-23

Washington, D.C. 90545

W. Purcell

Office of Civilian Radioactive Waste Management Office

U.S. Department of Energy

RW-23

Washington, D.C. 90545

P. J. Gross

U.S. Department of Energy Oak Ridge Operations Office

Oak Ridge, TN 37830

W. J. Madia

Battelle Memorial Institute BPMD

505 King Avenue

Columbus, Ohio 43201

C. P. Gertz

U.S. Department of Energy

785 DOE Place

Idaho Falls, ID 83402 
No. of

Copies

P. A. Bolton

Roy $F$. Weston, Inc.

2301 Research Blvd. 3rd Floor

Rockville, MD 20850

W. D. Woods

The Ralph M. Parsons Company

100 West Walnut Street

Pasadena, CA 91124

K. G. Golliher

P.0. Box 5400

U.S. Department of Energy

Albuquerque, NM 87185

J. R. Williams

U.S. Department of Energy

Salt Repository Project Office

$505 \mathrm{King}$ Avenue

Columbus, $\mathrm{OH} 43201$

R. W. Lambert

Electric Power Research Institute

$3412 \mathrm{Hillview}$ Avenue

Palo Alto, CA 94303

Don Vieth

U.S. Department of Energy

P.0. Box 14,100

Las Vegas, NV 89114

L. B. Shappert

Oak Ridge National Laboratory P.0. Box $X$

Oak Ridge, TN 37830

L. C. Rouse, Chief

Advanced Fuel Licensing Branch

Nuclear Materials Safety and Safeguards

U.S. Nuclear Regulatory Commission

Washington, D.C. 20555
No. of

Copies

J. W. Cashwell

Sandia National Laboratory

Department 6320

P.0. Box 5800

Albuquerque, NM 87185

W. E. Watters

EG\&G Idaho Inc.

P.0. Box 1625

Idaho Falls, ID 83415

K. H. Henry

Rockwell Hanford Operations

P.0. Box 800

CDC-1 Building

Richland, WA 99352

T. L. Sanders

Sandia National Laboratory

Division 6323

P.0. Box 5800

Albuquerque, NM 87185

30

DOE Technical Information

Center

\section{ONSITE}

3 DOE Richland Operations Office

R. D. Izatt

M. Dayani

J. J. Sutey

56 Pacific Northwest Laboratory

R. C. Adams

W. W. Ballard

A. J. Beogel

H. C. Burkholder

B. M. Cole

J. W. Currie

P. M. Daling

A. L. Doherty 


\section{ONSITE}

No. of

Copies

R. L. Engel

J. F. Fletcher

A. L. Franklin (3)

R. M. Gale

R. Harty

R. E. Heineman

C. J. Hostick

D. S. Jackson

$U$. P. Jenquin

R. L. Kathren

J. C. Lavender (20)

P. N. McDuffie

J. L. MCEl roy

G. W. McNair

P. J. Pel to

R. E. Rhoads

K. J. Schneider

D. J. Silviera

R. I. Smith

M. K. White

Publishing Coordination (2)

Technical Information (5) 


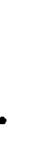

